\title{
The Pottery Informatics Query Database: A New Method for Mathematic and Quantitative Analyses of Large Regional Ceramic Datasets
}

\author{
Neil G. Smith • Avshalom Karasik • \\ Tejaswini Narayanan • Eric S. Olson • \\ Uzy Smilansky • Thomas E. Levy
}

(C) Springer Science+Business Media, LLC 2012

\begin{abstract}
There is an increasing demand within the humanities and social sciences to use computers to analyze material culture and discover patterns of historical and anthropological significance. Using southern Levantine Iron Age (ca. 1200-500 BCE) ceramics as a test case, the Pottery Informatics Query Database (PIQD) provides a novel solution for constructing regional ceramic typologies. Beyond digitally archiving 2D/3D-scanned ceramics, the PIQD encodes ceramic profiles as mathematical representations. This method of digital preservation enables rapid queries to be conducted in a mathematically grounded approach. In this sense, the queries are similar to online Basic Local Alignment Search Tool searches developed in the field of genetics by rapidly associating large quantities of digital vessel profiles to each other based on similar morphological traits. The PIQD is an open-source online tool that enables scholars and students to test humanities-related hypotheses against ceramic data in ways that conventional publications or other databases cannot provide. Regional spatial patterning of the ceramic data is delivered over a Google Earth-based user interface. In this paper, we present the PIQD as an objective method for developing a comprehensive ceramic typology of an entire region of archaeological study and provide an arena to conduct novel scientific research. We then demonstrate through a case study its analytical capabilities to handle large datasets of 3D scans and digitized 2D ceramic profiles and generate cultural inferences with the ceramic assemblages of the Iron Age II "Edomite" region located in modern southern Jordan. PIQD adds an important methodological tool to the post-excavation cyber-archaeology tool box.
\end{abstract}

N. G. Smith $(\bowtie) \cdot$ T. Narayanan • E. S. Olson • T. E. Levy

Cyber-Archaeology Laboratory, California Institute for Telecommunications and Information

Technology, University of California, San Diego, USA

e-mail: ngsmith99@gmail.com

A. Karasik • U. Smilansky

Computerized Archaeological Laboratory, Institute of Archaeology, Hebrew University of Jerusalem,

Jerusalem, Israel 
Keywords Archaeology informatics · Southern Levant · Cyber-archaeology ·

Digital $\cdot$ Iron Age $\cdot$ Ceramics $\cdot$ Database Management

\section{Introduction}

Since the early 1900s, print has been the primary medium for dissemination of archaeological excavation data. The backbone of all comparative theories, models, reconstructions of archaeology, and history still remains the published material contained within books and journals. In general, whether presented on paper or in online publications, this medium is very limited in its ability to inform other archaeologists not present at the excavations on the nuances of the material culture collected at the site, such as the relationship between the material culture assemblages, architecture, stratigraphy, and context. Traditional publication makes it extremely difficult for the reader/user to analyze artifacts in any technical manner. Although there has been increasing interest in the digitization of the archaeological record to help circumvent these limitations, methods for making these critical databases easily available to fellow researchers and the public are still in their infancy. The ability for researchers to analyze their own data against comparative data from other excavations has been a consistent obstacle to testing their theories critically and for developing comprehensive interpretive models. What is critically needed now during the current period of advancing computer technology are digital tools and methods to query large archaeological datasets in ways that conventional print data cannot provide. In addition, twenty-first century researchers need tools that will make it possible to integrate these data into future research projects in a "seamless" fashion. Such a resource would enable ongoing technical and comparative archaeological studies that can take advantage of modern statistical analyses (e.g., principal component analysis (PCA), cluster analysis, discriminate analysis), automated manipulation and organization of data, and rapid dissemination of results through many digital media.

In this paper, we introduce the Pottery Informatics Query Database as a solution to digitize, organize, query, and analyze volumes of published and unpublished ceramic assemblages from different regions and periods of archaeological study (Figs. 1 and 2). The Pottery Informatics Query Database (PIQD) is an online tool designed to enable researchers to test their own interpretations and models against the ever-expanding digital medium of ceramic datasets in ways that conventional print data cannot provide (http://adaa.ucsd.edu/PIQD). Beyond archiving published 2D vectorized images or 3D models of ceramics, this project uses recent technological advances developed by Karasik and Smilansky (2011) to mathematically encode and store the morphological data of the objects. The encoded storage enables the rapid search of the whole database of digitally stored vessels in an objective mathematically grounded approach. In this sense, these queries are similar to online Basic Local Alignment Search Tool (BLAST) searches (Altschul et al. 1990) developed in the field of genetics to rapidly associate large quantities of digital vessel profiles to each other based on similar morphological traits. However, the PIQD goes beyond the mathematical algorithms used to characterize individual pieces of pottery (and other realms of material culture) by providing a fully queriable spatial database that can conduct an assortment of multivariate analyses. 


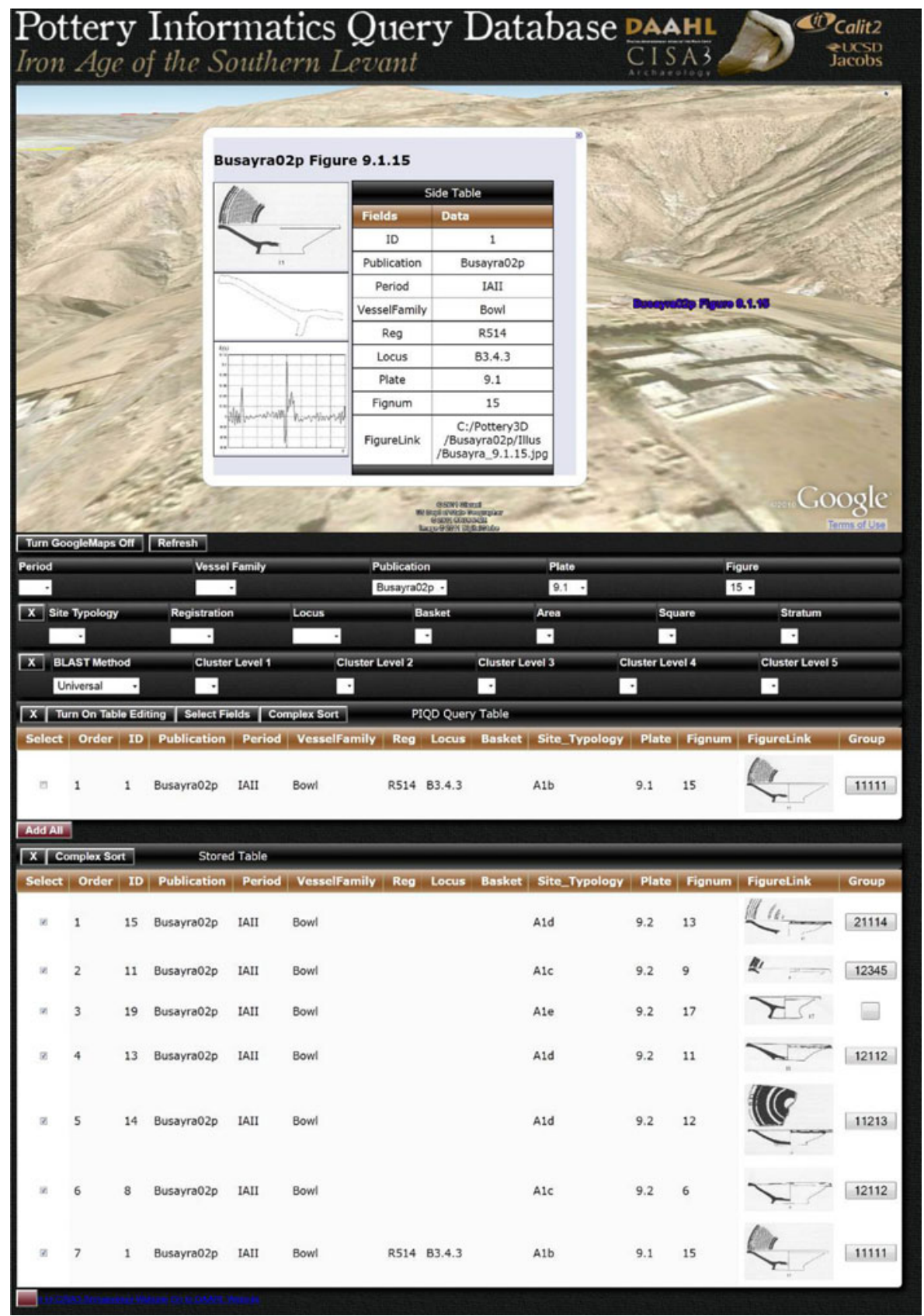

Fig. 1 Pottery Informatics Query Database Main Web Page (http://adaa.ucsd.edu/PIQD)

The Iron Age (ca. 1200-586 BCE) southern Levant was chosen as the initial study area for the PIQD because our data is "pre-adapted" to online storage and analyses, since every artifact collected in the field was georeferenced using digital recording tools (Levy \& Smith 2007; Levy, Najjar and Higham 2010, b; Smith \& Levy 2012). 


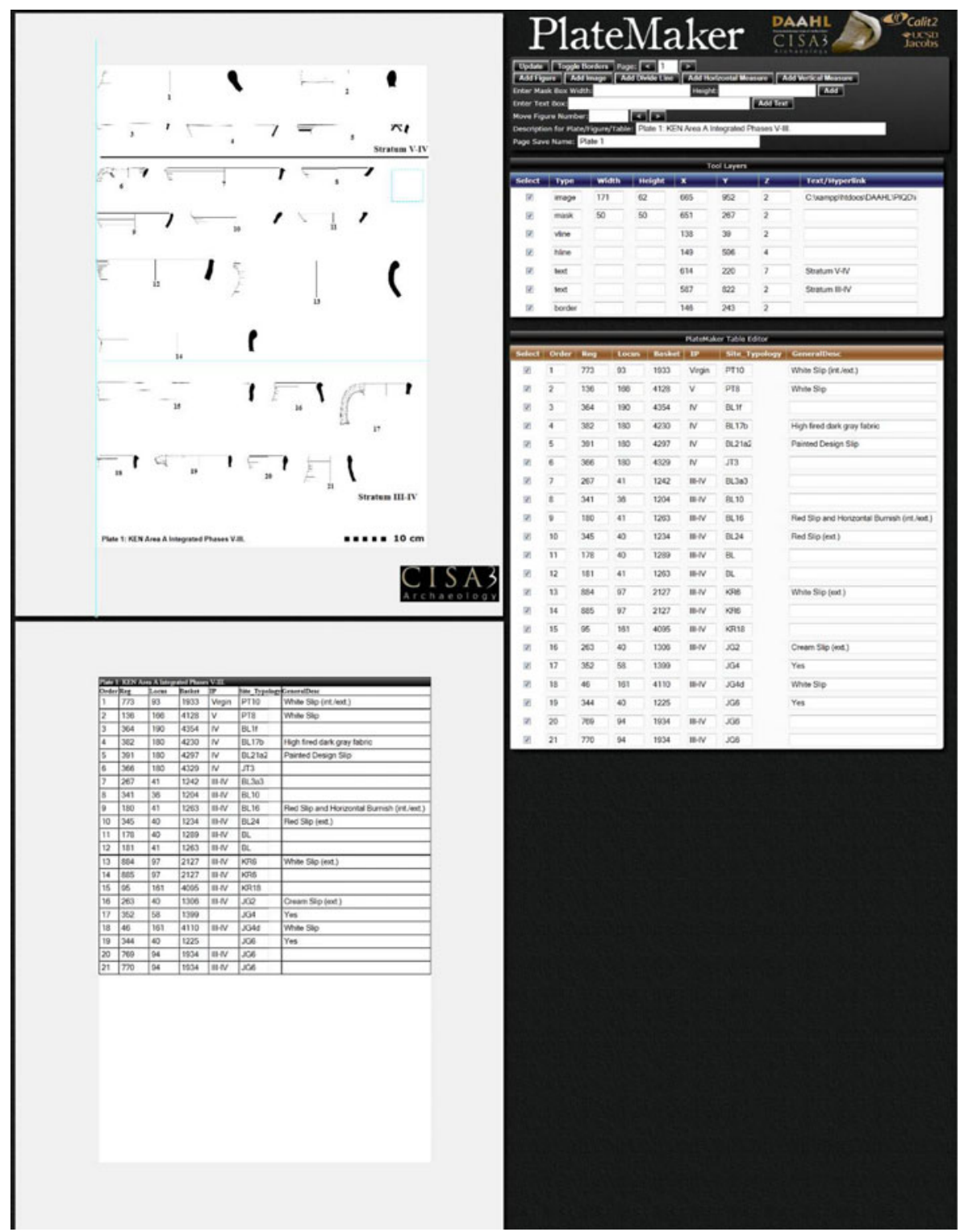

Fig. 2 The PIQD PlateMaker automates the production of ceramic plates and tables from user generated queries or studies generated in the PIQD. It facilitates the production of professional looking ceramic plates with little time and labor investments that are ready for immediate publication in print or online formats

In addition, the Iron Age of the southern Levant is a well-documented region with hundreds of excavated sites. The Iron Age period has also become a subject of intense ceramic typological debate over the relationship of certain vessel types to subperiods and their association with ethnic groups (Bienkowski and van der Steen 2001; Dever 1993, 2003; Edelman 2002; Finkelstein 1997; Faust 2006; Levy 2009; Whiting 2007). The scholarly discourse focuses on the tenth century BCE and issues concerning the historicity of biblical personages (David and Solomon), peoples 
(Israelites, Philistines, Edomites, Moabites, Midianites, and others) and locations mentioned in the Hebrew Bible and other contemporary ancient Near Eastern sources (Finkelstein 2005b; Finkelstein \& Silberman 2006; Finkelstein and Piasetzky 2009; Levy 2010; Mazar 2005, 2011; Mazar and Bronk-Ramsey 2008). These debates have driven ceramic specialists to corroborate their arguments with several other scientific fields of analysis, such as petrography, Instrumental Neutron Activation Analysis (INAA), X-ray fluorescence (XRF), Fourier transform infrared, and accelerator mass spectrometry radiocarbon dating (Goren 1996; Goren et al. 2004; Gunneweg et al. 1991a, b; Gunneweg and M. Balla 2002; Weiner 2010). This is also a period in which a number of ceramic assemblages have already been 3D scanned, so that we are not completely dependent on 2D-rendered profiles. By starting with the Iron Age southern Levant, we are able to present to a large community of archaeologists the research benefits of the PIQD and to provide a base dataset from which the PIQD can be expanded to different periods and regions.

In the following sections, we present how the PIQD can bring an objective method for developing a comprehensive ceramic typology of an entire region of archaeological study and provide an arena to conduct novel scientific research. We then test the analytical capabilities of the PIQD through a case study that seeks to address several typological problems in Iron Age II "Edomite" ceramics using both 2D and 3D datasets from Edom and contemporary sites throughout the southern Levant. While the application is region specific, the PIQD program can be applied to ceramic assemblages the world over. Finally, PIQD should be conceptualized as a prototype for a future "artifact informatics" program that can be applied to any realm of material culture (metals, lithics, ground stone, etc.) where typological analyses are important. In this sense, PIQD represents a significant contribution to the growing field of cyberarchaeology, which aims to integrate some of the latest developments in computer science, engineering, and the hard sciences with archaeology.

\section{Pottery Informatics for Southern Levantine Archaeology}

Pottery informatics can be defined as an objective method for analytically studying ceramic assemblages through the application of statistics and computer science that involve mathematical algorithms, complex relational databases, automated systems, and 3D digital recordings. The PIQD is a digital repository capable of storing all the Iron Age ceramic assemblages found in the southern Levant. It contributes to pottery informatics by enabling researchers to conduct complex queries and statistical analyses of these ceramic assemblages and conduct parallel or typological studies across the southern Levant during the Iron Age. The core function of the PIQD is to provide an easy search for parallels and an objective classification of ceramics at a much higher level of precision that can distinguish minute differences in ceramic morphological form. Consequently, the PIQD significantly improves upon the traditional methods of ceramic typology construction in the southern Levant. In this section, we present the methodology that underlies ceramic typology construction in the southern Levant, its drawbacks, and attempts to apply typologies to a region of study. We conclude with highlighting several of the advantages an automated classification can bring to a region. 
Research Area and Design of the Pottery Informatics Query Database

The preliminary research area of the PIQD has been the Iron Age II southern Levant (Fig. 3). Since 2002, the University of California, San Diego (UCSD) Edom Lowlands Regional Archaeology Project (ELRAP) and Lowland to Highlands of Edom Project (L2HE) in southern Jordan have focused survey and excavation on the Iron Age and understanding the social evolution of the inhabitants who resided in the territory known from ancient Near Eastern texts as "Edom" (Levy et al. 2003, 2005). Prior to our work, very minimal excavation had occurred in the area and only a small typology was constructed based on excavations at three sites dating to the Late Iron II period (ca. 800-500 BCE) located on the plateau of Edom. The appearance of the Late Iron II sites on the plateau coincides with the emergence of a capital city (Biblical Bozrah-modern Busayrah), writing, and "kings", which are not only

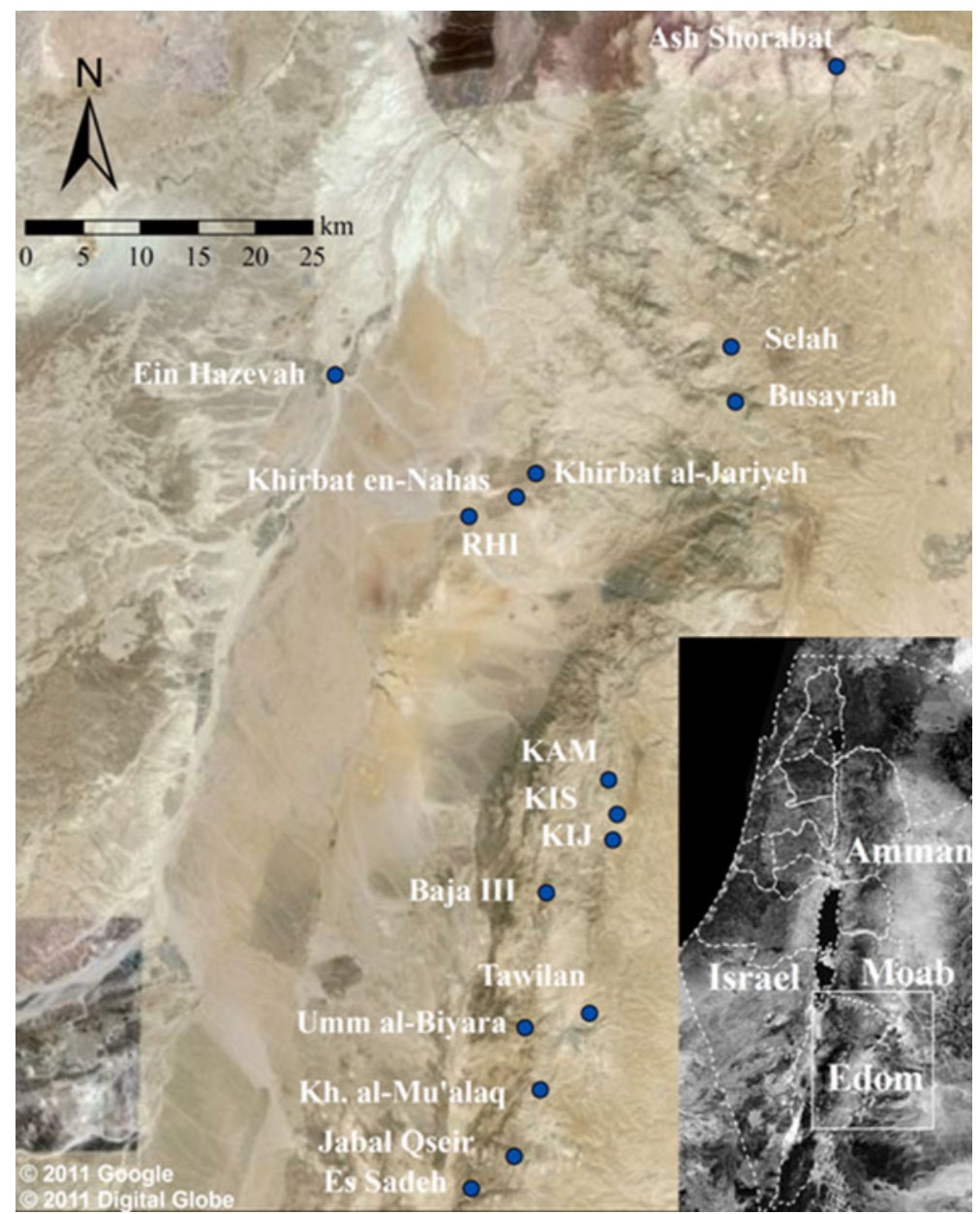

Fig. 3 Northern portion of assumed Ancient Edom territory with excavated or surveyed sites included in PIQD and mini map of southern Levant. RHI Rujm Hamra Ifdan, KAM Khirbat al-Malayqtah, KIS Khirbat al-Iraq S, KIJ Khirbat al-Kur (Iraq Junabiya) 
evidenced in the archaeological record but also the Hebrew Bible and Assyrian/ Babylonian documents. However, the origin of Edom's inhabitants during the Iron II or what triggered Edom's social evolution and explosion of new villages on the plateau is hotly debated and has led to a call to recover more archaeological evidence through survey and excavation (c.f. Bienkowski 1992; Finkelstein 1992, 2005a; Finkelstein \& Silberman 2006; Finkelstein and Piasetzky 2008; Levy 2004; Levy et al. 2005, 2008; Levy \& Najjar 2006; Levy, Najjar and Higham 2010a, b; LaBianca \& Younker 1995a, b). Moreover, the specific nature of the archaeological evidence for Late Iron II Edom suggests a social complexity betwixt and between a chiefdom and state that has driven significant scholarly debate and several different theoretical models (Bienkowski and van der Steen 2001; Knauf 1992; LaBianca and Younker 1995a, b; LaBianca 1999; Levy 2009; Porter 2004; Smith 2009).

The excavations at Khirbat en-Nahas (KEN) reopened the debate on Edom's social evolution when the first significant stratified site dating to the Early Iron II was excavated in the lowland zone where the region's main copper ore resources are located. The ceramic assemblage from KEN shares many distinctive stylistic traits of the later Iron Age, but its stratigraphy and large suite of radiocarbon dates place it in the Early Iron II period (ca. 1000-800 BCE; Levy et al. 2005, 2008; Smith 2009). The new ceramic assemblages recovered from Khirbat en-Nahas and neighboring Early Iron II sites necessitated a reevaluation of the ceramic assemblages found earlier in surveys and excavations on the plateau. A comparative ceramic analysis of all these assemblages enabled us to decipher not only chronological differences in ceramic styles but also sociopolitical and technological changes in the production and distribution of the pottery over the entire Iron Age II (Smith 2009).

The need to compare and analyze many large collections of ceramic assemblages presented in excavation reports was the impetus for the initial construction of the PIQD. The PIQD enabled us to store all of our UCSD excavation and survey ceramic data as well as directly analyze it with the growing database of all the other southern Levantine ceramic studies dating to the Iron II period. Although in previous research, we used the PIQD for organizing our ELRAP-L2HE data and to assist us in our typological classification of the local sites, in the case study presented in this paper, the PIQD is applied specifically to investigate regional typological questions using only the analytical capabilities of its built-in functions.

The PIQD is designed as an online queriable open-source Geographic Information System (Fig. 4). A PostgreSQL server database functions as the underlying structure to the system by interlinking all the data associated with each pottery sherd together, such as its stored raster image, vectorized profile, metadata (e.g., basket, locus, color, inclusions, etc.), type-code, typology system, 3D model, and spatial location. The database is designed to be comprehensive in its storage of archaeological data but with the addition of even more specific tables of information that are needed for comprehensive data analyses. These can be dynamically joined to it enabling more detailed studies. The PostgreSQL database and its related digital data are stored on a dedicated server located at the California Institute for Telecommunications and Information Technology (Calit2) at UCSD. An Apache web server controlled by PHP, JavaScript, and AJAX scripts is used to communicate between the file server, PostgreSQL database, web-based user interface, Google Earth API map, and the 


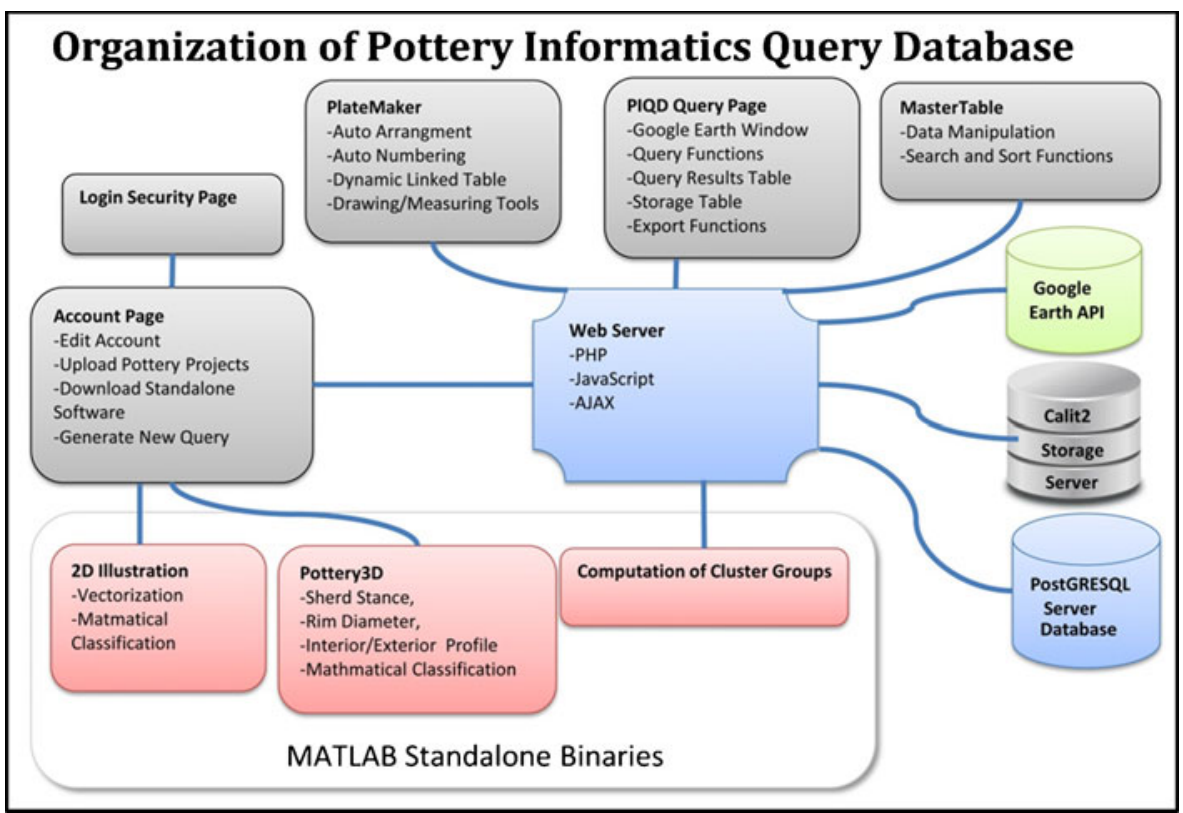

Fig. 4 Flowchart detailing organization of the Pottery Informatics Query Database (PIQD)

underlying MATLAB functions that drive the mathematical classifications. This project is integrated into the Digital Archaeology Atlas of the Holy Land project developed by Stephen Savage and Levy, which enables the PIQD to access its available spatial research tools and databases (see http://daahl.ucsd.edu).

The digital ceramic content of the PIQD is generated from 2D and 3D scans of ceramic assemblages and their metadata. The incorporation of new datasets is divided between a distributed group of students and researchers around the world who are invested in south Levantine Iron Age ceramic research. This is accomplished through providing digital content creation tools for processing $2 \mathrm{D}$ illustrations and $3 \mathrm{D}$ scans of ceramic data in a standardized digital format (e.g., Fig. 5). The method for incorporating ceramic profiles from 2D illustrations involves digitization (scanning) of published raster images and vectorization (conversion of raster images to vector representation of ceramic profiles). ${ }^{1}$ This technique and its accuracy for use in conducting typological analysis have been published elsewhere (Gilboa et al. 2004). The preferred method of incorporating 3D scans of ceramic diagnostic sherds follows a similar process of automatically computing a vectorized profile, stance, and diameter using a standalone MATLAB program called Pottery3D, designed by A. Karasik (Fig. 5) and presented here for the first time. Since both the final output of both the 2D- and 3D-derived profiles is a mathematical representation, they can be directly combined into a fully comprehensive analytical environment. In this manner,

\footnotetext{
${ }^{1}$ We store the digitized sherd in an array of $x$ - and $y$-coordinates describing the profile and its distance from its axis of rotation. The array is placed in a .mat: file stored on the server and can be directly accessed by the MATLAB standalone binary functions. Upon user request the raw vector format or normalized smoothed version can be dumped into a PostgreSQL table, for alternative programs to access the vector coordinates of the profile.
} 


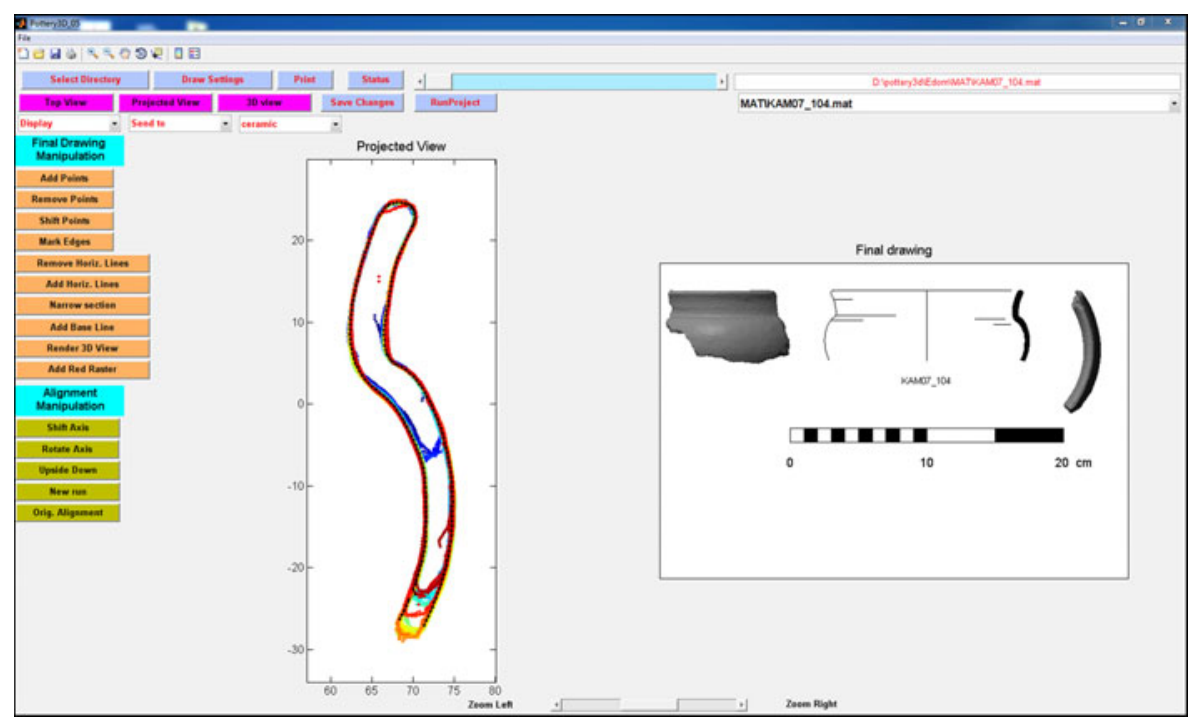

Fig. 5 The Pottery3D program designed by A. Karasik used for profile and stance extraction of ceramics 3D scanned

exponential growth of the PIQD is possible through placing content creation into the hands of a distributed user base while at the same time preserving and incorporating legacy published ceramic assemblages found in published materials. Maintenance of a high level of standardization and control of data uploaded is achieved while administrator intervention is minimalized. Currently, the PIQD has over 10,000 entries with ca. 3000 converted to a vector format for complex mathematical queries; however, the PIQD is designed to grow exponentially as new ceramic assemblages are added to the database. Every new digitized sherd is incorporated into the cluster analysis through an automated system. This is accomplished through the use of executable MATLAB functions that both perform a series of quality inspections on that data and compute new cluster matrices for the database allowing BLAST-like queries to be made without the overhead of continually recomputing the cluster analysis at every run cycle.

\section{Ceramic Typological Theory in the Southern Levant and Beyond}

There are several approaches to construct a ceramic typology of a geographic region (cf. Adams and Adams 1991; Banning 2000; Dunnell 1971; Gifford 1960; Read 2007; Rice 1987; Whallon and Brown 1982). Most ceramic typologies tend to emphasize either ware type or vessel morphology. In the southern Levant, morphologically based typologies have predominated, although the increasing use of petrographic, INAA, and XRF studies has led several archaeologists to consider these variables in their typological constructions (see references above). Morphological type systems emphasize attributes of a vessel's form. A number of techniques have been developed to measure and classify sherds by morphology, such as proportion ratios, vessel contour, geometry, or volume (c.f. Rice 1987:215-222). In the southern Levant, the type-variety method of typological construction is primarily used with a 
strong emphasis placed on a diagnostic sherd's morphological attributes (Banning 2000:42; Gifford 1960; Read 2007:85).

Fundamental to a type-variety method of classification is the definition of a type by a pattern of modes (Gifford 1960). In other words, a type is a group of diagnostic sherds or vessels sharing a set of similar reoccurring attributes among many other variant attributes. The types are derived from "discovered" patterns found during a comprehensive analysis of an entire ceramic assemblage. This approach is in contrast to classificatory-based typologies where types represent classes bounded by explicit predefined definitions that may or may not contain actual examples in the ceramic assemblage studied (Dunnell 1971). The versatility of the type-variety system is that it allows for idiosyncrasies within patterned attribute combinations that would typically break a typology based on classification. Therefore, while all members of the type may vary in some attributes, researchers are able to select particular exemplars of the group to serve as prototypes to represent the whole group. These prototypes are most commonly selected for illustration and publication of a site's ceramic assemblage. In practice, this method of typological construction also means that the types can change description as new exemplars are found of a group or information is added or subtracted (Banning 2000:42). In other circumstances, these groups can become constructs in which they become a predefined class that new data are assigned.

Whether it is a classification or grouping, the fundamental building blocks are the identified attributes. Dunnell (1971:49) defines an attribute as a “...unique and nonrecurrent quality of a specific instance in the phenomenological realm." In other words, an attribute is the smallest measurable value of a particular feature of an object. The identification of attributes on an object can be infinite and so attributes must be controlled or limited by a researcher's tools of measurement and the particular problem of classification they are seeking to solve (Dunnell 1971:50). In a classification, specific attributes are selected to address the particular problem of the classification and become the defining features of a class. In a grouping, it is the goal of the researcher to identify the significant attributes that cluster around an average. A group will contain an aggregate of these attributes that share a measurable similarity in occurrence (i.e., a pattern).

The utility of the type-variety system for ceramic typological construction is that it allows a researcher to generate inductively a working typology of newly discovered ceramic assemblages of a specific site and account for the idiosyncrasies of patterned attribute combinations. Since ceramic vessels were often produced around a specific technological or cultural style, vessel types are already predisposed to contain a set of fundamental attributes. A number of ethnoarchaeological studies have confirmed the role culture and socialization play in the construction of vessel styles, the selection of their attributes, and the level of standardization or consistency in which potters produce them (c.f. Arnold 1985, 1989; Deal 2007; Dietler and Herbich 1998; Lechtman 1977; Lemonnier 1986; van der Leeuw 1993; Stark et al. 1998). It is this aspect of the type-variety system that led Gifford (1960:343) to argue further that " [a] type is regarded as being the material outcome of a set of fundamental attributes that coalesced, consciously or unconsciously, as a ceramic idea or 'esthetic ideal' - the boundaries of which were imposed through the value system operative in the society by virtue of individual interaction on a societal level." Although it is flawed to think 
that a past culture's emic types can be easily discovered by the type-variety system as Gifford (1960) suggested, this does not preclude us from finding etic types that can be used to classify a ceramic assemblage. Second, ceramic vessel types found in the archaeological record were produced and exchanged by humans that led to significant idiosyncrasies in how one can classify types from an archaeological assemblage. These idiosyncrasies are due to the varying technical skill of potters, the role of human agency in their production, and the exchange of multiple potters' wares in a community that reflect a mixture of various styles and individual attempts at imitating specific types of vessels. Theoretically, the type-variety system circumvents this problem by accounting for this variance and focusing in on the particular attributes that would represent the various patterns of specific potters individual and culturally influenced behaviors of production with all of these sporadic attributes being relegated to background noise.

In the case of the southern Levant, typological construction moves back and forth from inductively discovered groupings using the type-variety system to clearly predefined classes. The initial stage of typological construction can best be described as "supervised classification" (Hand 1997). Diagnostic sherds are classified according to defined vessel family classes (e.g., bowl, jar, and jug) generally using morphological attributes such as proportional ratios of height to diameter and orifice to midsection diameter to determine what class they belong to (c.f. Shepard 1965). Vessels that do not fit into these defined proportional ratios and have distinctively different sizes, thickness, or morphological features are assigned to specifically defined classes (e.g., kraters, pithoi, vats, flasks, pyxides, cups, and cooking pots).

Although the majority of southern Levantine ceramicists use these classes, their definitions are not always precise or necessarily agreed upon. Ceramicists use slightly different criteria to distinguish between a bowl and cup, krater and large bowl, jar and pithos, or jar and cooking pot resulting in conflicting typologies at the most basic level of classification. Even the delineation between jars and jugs fluctuates, especially in situations where a handle is not present on a closed vessel. Ceramicists working in the southern Levant often adopt methods from their mentors that they have "internalized" and learned how to interpret or convert other ceramicists typologies into their preferred classification system to overcome inconsistency (c.f. Whittaker et al. 1998). Ceramic forms that do not fall into the set categories tend to be underemphasized and relegated to the miscellaneous sections of publications rather than having new classes created to account for them.

Once these vessel family classifications are made, a type-variety system is used to "discover" types and their variety of attributes. However, the varying emphasis on what are considered the important attributes of a type and the scale at which attributes are defined result in much of the contradictory typologies of the southern Levant. The groups are determined through analysis of the various attributes of the pottery and identification of patterns or similarity of re-occurring attributes that converge around an average or mode. The consideration of what attributes play the greatest role in determining groups varies between southern Levantine ceramicists, but often attributes of the body of the vessel (the area between the orifice and base) generally takes first rank in the grouping process. The attributes of vessel body can be geometric attributes (e.g., rounded, flaring, cylindrical, globular, and ovoid) and/or structural attributes (various forms of carination, distance between inflection points, presence/ 
absence of a shoulder or neck). Although generally, rim treatment follows the grouping of the body, in certain circumstances it may be considered by the ceramicist as a defining attribute in which various body attributes are linked (e.g., repeated patterns of unique rim treatments on varying body forms). Attributes of rim treatment can be combined to include rim stance, thickening, subsequent folds, grooves, ridges, diameter, attachments, specific treatment of the lip, etc.

During the inspection of these attributes, there is an inconsistency on what scale of measurement is considered definitive. For example, two diagnostic sherds maintaining a similar profile may differ by a few centimeters of thickness of body or rim. If this variance is not considered significant, the sherds are grouped together "lumped," while if it is considered significant a new group is formed "split." According to Dunnell (1971:55), the scale of inspection will determine at one level an attribute being seen as unique but at a higher composite. Ceramicists working at different scales of inspection will inevitably develop different typologies and more importantly fail to agree upon distinctions that may be considered chronologically or spatially significant. In sum, the importance at which different attributes take in creating types extremely varies between one ceramicist to another and thus leads to conflicting typologies. Although a conscious effort is made to inductively discover what attributes are most relevant for morphological classification, these attributes and their clustering into types is not regularly validated by southern Levantine ceramicists.

The notion that typological classifications are arbitrary and inconsistent is not new. In fact, most archaeologists consider variation between typologies to be inevitable and in some circumstances seek to account for them through validation of their own typological system. However, validation of one's own typology is not easily accomplished or necessarily leads to a more agreed upon typology for a region of study. For example, Dunnell (1971) argued that despite the arbitrariness of how classifications may be created, they should still be able to be evaluated if they are going to be useful to other archaeologists. Building upon this assumption, Adams and Adams (1991) emphasize that the researcher must develop their typology with clearly developed definitions and hypotheses that target what they wish to learn or achieve. Validation is achieved when the researcher satisfies the objectives of their research questions which are clearly defined. Yet, this form of validation does not eliminate other alternative typologies by other researchers since the only criterion for validation is the premade assumptions of the researcher which often are not "self-evident" (Read 2007:70). Moreover, Whittaker et al. (1998) note in their study that even when archaeologists employ the same analytical techniques on the same collection, different conclusions are often made. Validation of a typology is not accomplished when an individual researcher feels they have satisfied their objectives. This type of validation will never converge to a systematic typology over time (c.f. Whittaker et al. 1998:135). A fundamental element of any scientifically based typology is not only its validation by the researcher but that the results are found consistent and reproducible among a group of researchers. Despite the arbitrariness that exists in any typology, validation and consistency found by different observers is fundamental if the typology is to serve any utility beyond a single sites' ceramic typology (Read 2007:105). Therefore, the typologies that would make any broader claim to archaeological debates of a region should seek to provide a means in which they can be validated by other researchers and generate consistency among them. 
Regional Typological Classification in the Southern Levant and Approaching Objective Typologies through the Pottery Informatics Query Database

The problem of ceramic typological classification is compounded, when it is used to search for parallel examples in different strata of a site or other "contemporary" sites. This leads to the inability for an agreement to be reached between different researchers holding conflicting typologies that would make claims as to how sites may be dated, associated with specific groups' activities, or used as evidence to support greater archaeological debates. As mentioned earlier, this is a fundamental problem that has arisen in the southern Levant and has forced researchers to have to pick sides on larger debates such as the "Low verses High Chronology" where pottery types have traditionally been used to establish chronological systems rather than radiometric dating methods (see debates in Levy \& Higham 2005). There are a series of different problems that arise out of subjective typologies that can be seen in these types of debates. For example, a ceramic type that one ceramicist may note is found occurring in several areas, another ceramicist will point out attributes that they consider disqualify it as a parallel (i.e., debate over Collared Rim Pithoi in Jordan and Israel: Artzy 1994; Finkelstein 2011; Herr 2001). Second, certain types that one archaeologist may consider specific to a stratigraphic period is noted by another to occur earlier, later, or span a greater period of time. Generally, ceramicists must defend the reasoning and hypotheses behind every classification through detailed explanation for every type and the key attributes that link it to other site's ceramic assemblages. Moreover, since these studies typically are focused on the ceramic assemblage from one site, groups are discovered from the data that is available. Any addition or subtraction of information changes these descriptions of groups or refines them, thus one site's definition of groups will always be different from another. Groups found to coincide with specific stratigraphy of one site may not yield the exact same patterns in another. The result being that typologies can become site biased in their determinations of what definitions make up a type that are then compared across a region of sites. Additionally, ceramicists' ability to construct parallel studies is often limited by their dependence on only illustrations from other sites. This can result in the development of a different typology from those that have direct access to the materials who can notice more nuanced differences of attributes not easily depicted in a small black and white 1:5 scale illustration. Fourth, although most publications will cite morphological parallels from neighboring or wellpublished sites, they are not generally comprehensive regional studies of ceramic typology; these more comprehensive studies are rare and only occur once a decade (e.g., Amiran 1969; Dornemann 1983; Gitin 1990). Finally, all morphological studies become out of date once published. They cannot address new excavations and discoveries that may rapidly develop in the region. Often, a site that is excavated during the same season as another may not have its ceramics published until many years after the other site's publication. In a printed form, a typological classification can only be changed by a new publication that addresses the new datasets, but rarely this occurs.

Thus, the debate over the relative chronology of southern Levantine Iron Age sites has always been hampered by the subjectivity of ceramic classification, with researchers often talking past each other. In addition, the limitation of publication 
to paper media has prevented other researchers from adequately assessing the validity of others' typological constructions. The individual typologies may meet the objective goals of the researcher but their utility for conducting regional-based studies is limited. Thus, a fundamental goal to properly date a site by a relative ceramic chronology is a subjective enterprise. As mentioned above, for the southern Levant where ceramic dating plays such an important role in understanding greater anthropological and historical issues, this subjectivity only exacerbates the problem.

Although ceramic typologies will never be completely devoid of elements of subjectivity, we argue here that the PIQD provides objective methods to improve consistency and validation so that ceramic classifications can be used to answer greater archaeologically related questions. We suggest that the PIQD encompasses three essential elements of a typological classification that enable consistency and validation. These are: the digital measurement and objective selection of attributes, multivariate analyses that combine regional time and space attributes with the mathematical classifications, and comprehensive large datasets that can be continually evaluated by multiple users and improved.

\section{Digital Measurement and Objective Identification of Significant Attributes}

The PIQD uses mathematically based objective methods to both measure and select the relevant attributes used in its typological construction. This eliminates a significant portion of the arbitrariness in attributes found in typological classifications as documented by past studies (e.g., Banning 2000, Whittaker et al. 1998). For example, the study on consistency in ceramic typologies by Whittaker et al. (1998:134) found that "attributes are always selected by the analyst, and therefore attributes - and the types they define - are always affected by the problems and the biases of the investigator." They argue, in contra to Adams and Adams (1991), that observers' perceptions and expertise hinder their ability to be consistent even with explicit detailed definitions (Whittaker et al. 1998:142). In the study of Whittaker et al. (1998:142), the more experienced ceramicists made more attribute distinctions than the less experienced. The more experienced were labeled "splitters" in comparison to the "lumpers" because their classifications were based on much more nuanced identification of attributes and their a posteriori knowledge of other site's published classifications. Thus, the varying experience and particularisms of the researchers involved can make arriving at similar conclusions sporadic. Banning (2000:48) similarly argues that a primary element that results in the failure for researchers to reach objective and consistent conclusions is the initial decisions made in their selection of attributes, as demonstrated in the study by Whittaker et al. (1998). Banning (2000) and Whittaker et al. (1998) list several factors that lead to arbitrariness in the selection of attributes: how they are measured, what measurements are considered significant, the overall count of measurements, small errors in measurement, ability of the researcher in making proper measurements, and changes in sample size. The fundamental problem is that until recently the measurement and identification of attributes has relied upon human capacity to perceive attributes and properly measure them.

The PIQD is a tool designed to resolve this problem by using mathematical algorithms to both measure and identify statistically significant attributes. First, the PIQD relies upon 2D and 3D digitization of ceramics that provide an automated and 
highly precise recording method that can diminish measurement errors and reliance on researchers' expertise or perception. The entire morphology of the ceramic vessel is converted into precise measurements of its curvature, stance, and internal diameters. These are the essential measurements from which any possible morphological attribute can be derived. In the case of the 3D scans, ceramic profiles are calculated from the entirety of the vessel scanned not just one section. The measurement of the entire vessel is at the micron level of precision that is beyond what can be measured with a digital caliper or human perception. Even with the 2D scans of illustrated ceramic profiles, the digitization and conversion of the profile enables a unique morphological profile (fingerprint) to be generated for each vessel. Second, what measurements are considered significant and assigned as attributes are mathematically discovered rather than arbitrarily pre-assigned by an observer (see "The PIQD's Theoretical Approach to Automatic Classification and Mathematical Representations of Ceramic Morphology" section for a technical explanation of the mathematical methods alluded to here). This method is different from past mathematical typological classifications where the attributes considered significant were first selected and measured by the researcher and then used as input to determine their statistical relevance (c.f Plog 1980; Read 1982; Shennan 1988). Finally, the veracity of the selected attributes can be empirically tested according to the nature of their statistical significance (see “The PIQD's Theoretical Approach to Automatic Classification and Mathematical Representations of Ceramic Morphology" section). No matter how many times the statistical study is run or weights are changed, the results are consistent, explicitly defined, and evaluable.

\section{Regional Time and Space}

Beyond a purely morphological comparison of attributes, spatial and temporal attributes of an entire region can be combined to further validate the classifications made or discover greater nuances of ceramic types across time and space. For example, Banning (2000:53) argues that "a statistical association between intrinsic attributes does not verify a typology, but a statistical association between categories (types) of a typology and the spatial, chronological, social, functional, or ideological context would indicate that the typology is useful. (e.g., a specific type occurring in only Stratum I)." The accuracy of a type's definition is best verified through regional comparisons of time and space (Read 2007:105). In the PIQD, we have sought to be exhaustive in providing possible fields of different types of commonly measurable attributes that analysts use in their studies. Attributes related to provenience such as site location, stratigraphy, and locus provide a wealth of spatial and temporal information, are precise, and rarely prone to error. These attributes along with others can be easily applied to the morphological types to determine where types occur geographically and over spans of time and further evaluate the veracity of the mathematical typological classification.

\section{Large Sample Size and Continuous Evaluation}

A fundamental objective of the PIQD is to provide accessibility to a large body of researchers to evaluate the typologies mathematically generated, compare them to 
their own typologies, and provide rapid access to the most current published and unpublished ceramic assemblages in different archaeological regions of study. A common practice of any statistical study is to ensure the data sample is large enough to generate significant results. In the case of ceramic classification, large datasets enable groups to be more comprehensive and the patterns to stand out more clearly. The PIQD provides a consistent and highly precise arena for ceramic analysis that overcomes the drawbacks of the majority of parallel studies that depend on paperbased publications. It can rapidly create a verifiable classification that brings organization to an otherwise massive unorganized collection of thousands of ceramic profiles stored on a database. Secondly, it facilitates the user to locate and find the essential data they are interested in and discover unique patterns when they apply other variables to the data. The PIQD is an attempt to bring typological consistency through inviting many analysts to the table, providing them the same tools to analyze the data, and storing comprehensive large ceramic datasets to overcome myopic studies of typology. Evaluation of the typologies is freely available to any researcher and their input can help in refining these typologies. Evaluations by multiple researchers of the same assemblages are perhaps the best method to eliminating gross errors and the random noise of classifications (c.f. Whittaker et al. 1998:135). The PIQD serves as a vocabulary for communication bringing greater interproject comparability that could not easily be performed before. It also has the flexibility to grow and change through user correction and contribution of new ceramic datasets. Finally, although not every possible attribute that future archaeologists might want to consider can be anticipated, the ceramic data is controllable through a well-supported programming language that can be reconfigured on the fly. Incorporation of other methods of objective ceramic classification or attribute measurement is fully possible with minimal effort (i.e., XRF, INAA, thin section analysis, accelerator mass spectrometry radiocarbon dating, color spectrometer readings, etc.). In essence, the PIQD is flexible allowing new attributes that are considered important to classification to be integrated very easily into the system.

In sum, the PIQD brings a method in which typological classifications can be validated and provide at the same time a digital medium in which more nuanced and informed parallel studies can be carried out on a regular basis. The PIQD provides a very consistent and objective method that will hopefully be useful in resolving anthropological archaeological debates not only in the southern Levant, but in other regions in the world.

\section{Past Methods of Automatic Objective Ceramic Classification and Development of Ceramic Information Databases}

A survey of the archaeological literature shows that the concept of applying computers to generate ceramic classifications and store large datasets of ceramic information in databases is not new (Bishop et al. 2005; Durham et al. 1995; Hall and Laflin 1984; Kampel and Sablatnig 2003; Lengyel 1975; Lewis and K. J. Goodson 1991; Liu et al. 2005; Main 1978; Sablatnig and Menard 1997; Schurmans et al. 2001). However, these attempts have primarily focused on small datasets; simple methods of ceramic classification and have not progressed beyond their initial demonstration phases. Currently, ceramic "databases" available to the research 
community fall under three categories: (1) catalogs of ceramic finds from an excavation in an online table form ${ }^{2}$; (2) databases of images of prototypical complete vessels $^{3}$; and (3) simple query databases that search ceramic metadata by keywords. ${ }^{4}$ The PIQD improves upon these databases by not only its expandable method of digital storage and organization, but also its ability to function as an analytical tool for rigorous multivariate studies and evaluation of mathematical typological classifications.

There are several projects that have advanced this field of research that could be considered predecessors to the PIQD. For example, in 1990, Lewis and Goodson designed the Graphically Oriented Archaeological Database. The database stored ceramic attributes and raster images, which could be accessed to generate a classification of the ceramics based on the generalized Hugh Transform (GHT). Durham et al. (1995) improved upon the organization of the database and its classification system by developing a graphical user interface that accessed the database and could conduct real-time matching of ceramic artifacts using GHT. The standalone program called (SMART) ran on a sun-workstation or X-windows. One advantage of SMART was its ability to find matches using both profile drawings and digital images of the actual vessel. ${ }^{5}$ In 1997, Sablatnig and Menard (1997) presented a paper on a database designed to handle storage, analysis, and automatic classification of pottery. The database was designed to use as input in the classification both morphological shape features and descriptive properties of the sherd (e.g., clay, color, and surface). The database could be queried to find the top five most similar vessel types. The advantage of their approach was that not only morphological form but also the common descriptive attributes used by archaeologists (e.g., color, fabric, etc.) could be used to narrow down their similarity index. In 2001, an National Science Foundation-funded project called 3DK was presented by Schurmans et al. (2001) that described the creation of an artifact database to organize pottery, lithics, and bones. The initial demonstration used a small database of 87 3D-scanned complete vessels. The $3 \mathrm{D}$ scans were used to extract measurements on height, rim diameter, volume, and the outer profile curve of the vessels. Their method dealt with complete vessels which did not involve the more difficult process of estimating the proper stance and rim diameter nor averaging fluctuations in the symmetry of the profile. The database used an XML schema for storage and retrieval of information. The theory behind their approach was to "...use the shape grammar and shape algebra to provide a natural language syntax to write a shape as a construct of tokens (CPPs) and combination rules". For querying the database, they created a graphical user interface called 3DK that could use the determined CPP's to match metadata and vessel

\footnotetext{
${ }^{2}$ The Pottery of Lerna IV (http://csanet.org/archive/adap/greece/lernpot/lernameta.html); PRAP Pottery Database (http://docs.classics.uc.edu/fmi/xsl/prap/pottery_list.xsl?-findall); Worcestershire Online Ceramic Database (http://pottery.rigorka.net/\#cms/view/worcestershire_on-line\%20ceramic\%20database); Saint Mary's University Archaeology Lab Ceramics Database (http://www.smu.ca/academic/arts/anthropology/ ceramics/welcome.html).

${ }^{3}$ FARLI (http://apd.farli.org/home); FAMSI Mesoamerican pottery database (http://research.famsi.org/ rollouts/rollout_search.php).

${ }^{4}$ Hayton Roman Pottery Database (http://ads.ahds.ac.uk/catalogue/archive/hayton_eh_2007/index.cfm); Gallo-Belgic pottery project (http://gallobelgic.thehumanjourney.net/GB/index.php)

${ }^{5}$ See "The PIQD's Theoretical Approach to Automatic Classification and Mathematical Representations of Ceramic Morphology" section on the drawbacks to the use of GHT for classification.
} 
morphology and output the results with thumbnail images on a dynamic webpage. Each result could be clicked on to open a new page with all the information associated with the sherd. Although links to the online version no longer exist, the project is still currently being developed by the ASU I3dea group (http://i3dea. asu.edu/i3dea_projectDetail.php?recordID=47).

Although all of these database query projects were successful in demonstrating the possibility of developing an objectively based pottery query database, none of them were developed beyond their initial demonstrations to handle the type of demands ceramic specialists would require from such a database. First, all of these databases were small containing no more than one hundred entries (almost all complete vessels) and only a handful of fields to describe different attributes of each entry. It is typical among excavations in the southern Levant, and no doubt in other regions, that a single season of excavation can recover over a thousand diagnostic sherds that have to be recorded, analyzed, drawn, and compared to thousands of sherds found in published materials. A host of attributes are involved in this process, such as provenience (locus, basket, square, etc.), stratigraphic context (stratum, phase, and period), detailed description of form, and description of fabric (color (interior, exterior, and core), inclusions, texture, hardness, etc.). Ceramicists need a complex database to store all the possible fields of entry, to quickly find any entry, and make changes to it upon further examination. They also need to be able to look up parallels of their data to published material without having to search one by one through a bookshelf of published material. Spatially, they need to see the plotted location of pottery and their parallels in a region over time and space. Once they have completed their analysis, they need to combine their data tables with associated illustrations to publish a representative sample of the ceramic assemblage. A core goal of the PIQD is to address these demands to organize, edit, analyze, draw parallels across published material, and publish results.

Second, the classification methods used by previous projects would not be extremely applicable to ceramic specialists, especially working in the southern Levant. The main drawback of these previous studies is their reliance upon whole vessels and extracting the exterior shape of their profiles. With southern Levantine Iron Age assemblages, variation in form is a product of both the exterior and interior of vessel profiles. With a complete vessel, it is very simple to find matches with other complete vessels from just the exterior because one has a full picture of its profile. But once broken, diagnostic sherds are involved (which are the majority ceramic finds in most excavations), they can be mismatched with a variety of vessel forms if the exterior profile is only examined; their stance, diameter, and interior profile play a predominate role in how ceramicists are able to find parallels. It is these factors that also must be considered during $3 \mathrm{D}$ scanning, because low resolution scans with poor $360^{\circ}$ registration, errors along sharp edges, and oversimplification will generate unusable profiles for accurate classification. As will be further discussed in the next section, for an objective classification to be made that rivals the keen eye of a ceramic specialist, a more complex algorithm for profile matching needs to be applied.

Finally, perhaps the greatest drawback to all of these earlier studies is that they were not designed from the beginning to grow. It is disconcerting that none of the 
projects discussed above are accessible today. As mentioned above, the databases that are available online are not designed to handle any type of complex query or classificatory analysis. The purpose and intent of the PIQD is to design an online database that grows exponentially as more researchers find it as a tool to analyze their data and easily release their digital ceramic assemblages in conjunction with their traditional publications. It also provides a simple method to add any of the thousands of past excavation's published ceramic assemblages to the database. We expect in the near future to double the amount of site-published 2D ceramic illustrations through the use of student volunteers participating in the project and by students from other universities that seek to contribute. Moreover, at UCSD, the Hebrew University, University of California, Los Angeles, and Andrews University ${ }^{6}$ our method for 3D scanning and profile extraction of ceramic sherds is being integrated into the PIQD so that as these universities scan their pottery assemblages, they can be added first to stand-alone versions of the database and after publication to the online version. As the PIQD is expanded in its repository of ceramic data, it is also planned to expand its versatility in analyzing these data through user requests and collaboration with other projects.

\section{The PIQD's Theoretical Approach to Automatic Classification and Mathematical Representations of Ceramic Morphology}

As discussed above, in the southern Levant, among all attributes that are used for typological definitions of ceramics, morphological characteristics have been traditionally the most dominant factor. It is the morphological shape of vessels that rapidly changed over time and space, and therefore it is the most indicative variable for many archaeological questions. Since common pottery has a circular symmetry, a convenient and a concise depiction of the whole vessel can be achieved using its crosssection profiles. A digital representation of these profiles using mathematical descriptions, and comparing them with an objective statistically valid method is the key to our approach. This digital and analytic approach introduces new objective standards in a domain that was generally influenced by subjectivity. Moreover, it enables a straightforward use of the computational and statistical tools that not only save time and effort but also add accuracy and validation to one's conclusions. This approach is based on an innovative method that was developed in the last few years and can be defined as an automatic typology and classification of ceramics. It uses mathematical representations of ceramic profiles for their objective description and typological analysis, using digital representations from scanned 2D illustrations or from 3D models (Gilboa et al. 2004; Karasik et al. 2005; Saragusti et al. 2005; AdanBayewitz et al. 2009; Karasik and Smilansky 2011).

\footnotetext{
${ }^{6}$ The main projects currently involved include the Edom Lowlands Regional Archaeological Project codirected by T.E. Levy (UCSD) and M. Najjar (Jordan), Lowland to Highlands of Edom project co-directed by N. Smith (UCSD) and T.E. Levy (UCSD), Tel Dor project co-directed by A. Gilboa (Hebrew University and Weizmann Institute), The Jaffa Cultural Heritage Project co-directed by A. Burke (UCLA) and M. Peilstocker (IAA), and the Madaba Plains project including directors O. LaBianca (Andrews University), R.W. Younker (Andrews University), L.G. Herr (Canadian University College), and D.R Clark (La Sierra University).
} 
The concept of fitting mathematical parameters to pottery profiles is not new. Most of the early studies are summarized in the fundamental book of Orton et al. (1993). For instance, the contour of flint tools represented by Fourier transform was used by Gero and Mazzullo (1984); series of radii from the center of pottery silhouette was used to described their shape by Liming et al. (1989); the curvature function was used by Hagstrum and Hildebrand (1990); and the tangent function by Leese and Main (1983; Main 1978). However, none of these studies were used for classification, typology, or intensive comparison of vessels shapes. Had 3D scanning been available to the earlier researchers, it would have enabled them to extract accurate ceramic profiles. Thus, the recent development of a range of 3D laser scanning tools has been a "game changer" in computerized artifact typological research.

Thus, in the past two decades, more and more archaeological research groups have integrated 3D scanners for pottery documentation and research (Halir 1999; Adler et al. 2001; Leymarie et al. 2001; Razdan et al. 2001; Yao and G. Shao 2003; Kampel et al. 2005; Mara 2006; Karasik 2008a, b; Karasik and Smilansky 2008). Some have also developed a designated algorithm for automatic extraction of intrinsic measurements or other useful information such as the profiles of the fragments. The PIQD seeks to take this method for automated ceramic typology construction to a regional scale using the automatic classification system presented here.

This analytical method, which automatically classifies a given set of ceramic profiles, is based on accurate mathematical representations of the profiles, and has shown very promising results so far. It was tested in several cases and proved to be archaeologically meaningful and relevant (Gilboa et al. 2004; Karasik et al. 2005; Karasik and Smilansky 2008, 2011; Adan-Bayewitz et al. 2009; Karasik 2010). The classification method was published recently and its full description and formulas and details can be found in this publication (Karasik and Smilansky 2011). However, an overview of the formulas and their underpinnings are briefly presented here. The concept at the heart of our method is to consider the cross-section profiles as planar curves. Each curve is further represented by three mathematical functions - radius, tangent, and curvature. Mathematically speaking, each of the three representations of the profile stores the entire morphological information of the curve. They have oneto-one correspondence and each can be fully reconstructed from the other without any loss of information. They differ, however, in the sort of features to which they are most sensitive. The radius primarily displays the gross features of the profile such as its size and mean inclination. The tangent focuses on the stance of the sherd and is sensitive to local variations and details, whereas the curvature emphasizes in the most conspicuous way the finer features of the profile, e.g., rim treatment, carination, grooving, etc. Figure 6 shows two examples of ceramic profiles and its corresponding three mathematical representations. The differences between these representations are the basis for our comparison method. Namely, the sum of deviations between the mathematical representations serves as the distance measurement between the corresponding vessels.

This distance between profiles is measured in terms of the Euclidean distance between their corresponding representations (Karasik and Smilansky 2011). Moreover, we attach weights for each representation (radius, tangent, and curvature), that one can adjust in the various steps of the classification (see below). 

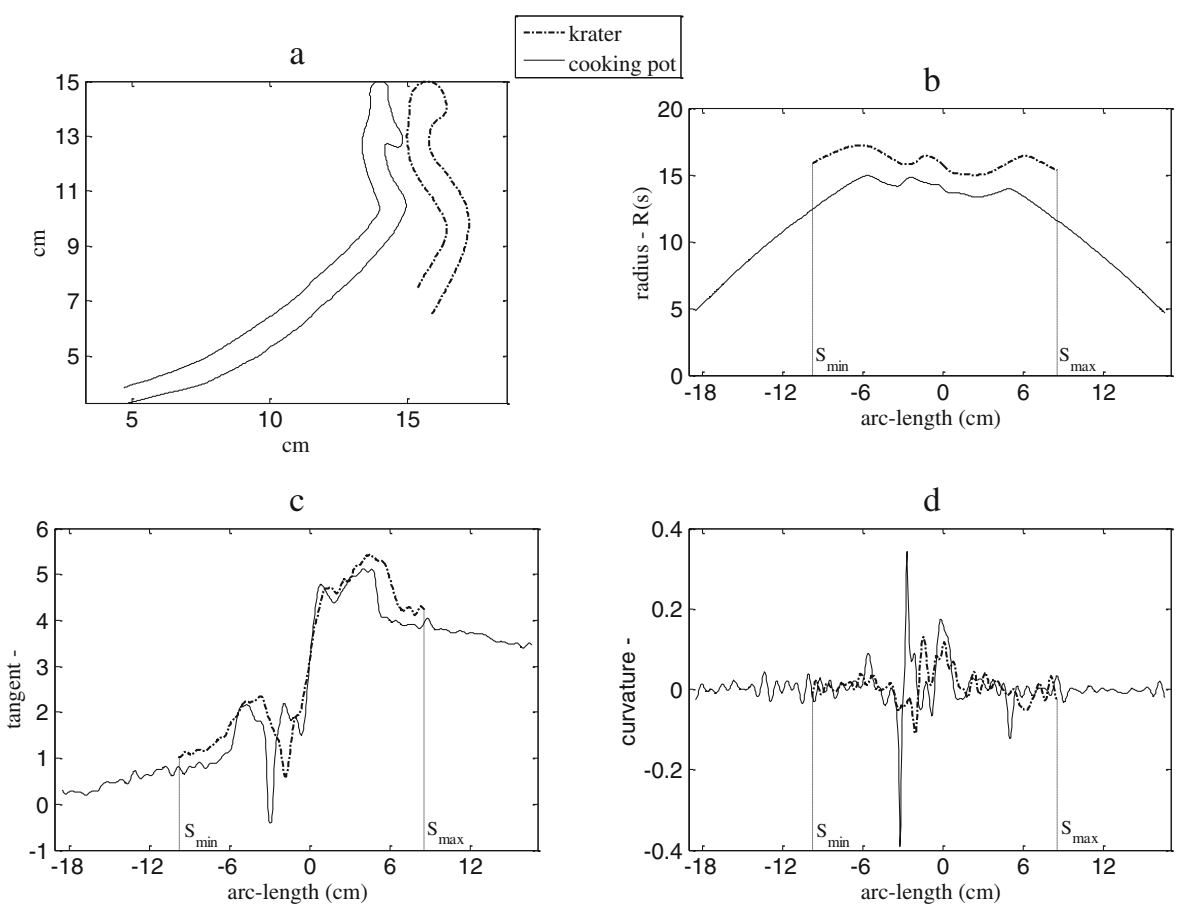

Fig. 6 Two profiles of a krater and a cooking pot (a), and their representative mathematical functionsradius (b), tangent (c) and curvature (d) (from Karasik and Smilansky 2011)

Given two profiles (denoted by $\alpha, \beta$ ), we define the distance between one of its representations (denoted by $x$ ) as:

$$
d_{x}(\alpha, \beta)=\sqrt{\frac{1}{L} \int_{S_{\min }}^{S_{\max }}\left[X_{\alpha}(s)-X_{\beta}(s)\right]^{2} \Omega(s) d s}
$$

In this formula, $s$ is the parameter that goes along the arc length of the curve with total length of $L$, and $\Omega(\mathrm{s})$ stands for a (positive) weight that allows emphasizing different parts of the profiles. This additional freedom becomes very handy when the archaeologist decides, e.g., that the rim shape is more significant than the base shape. In this case, $\Omega(s)$ will be larger near $s=0$ which is the rim area (Karasik and Smilansky 2011). The subscript $X$ indicates that the distance can be defined with respect to the radius, tangent, or the curvature function. The intuitive meaning of the definition of the distance is quite clear: it is the root mean square deviation between the two mathematical functions. It is clear that the distance between profiles vanishes if and only if they are identical. Thus, when all three representative functions are combined, the modified definition of the distance between the profiles simply sums the normalized distances of the three functions: $d(\alpha, \beta)=\omega_{x_{1}} \cdot d_{x_{1}}(\alpha, \beta)+\omega_{x_{2}} \cdot d_{x_{2}}(\alpha, \beta)+\omega_{x_{3}} \cdot d_{x_{3}}(\alpha, \beta)$.

Here, $\omega_{x_{1}}, \omega_{x_{2}}, \omega_{x_{3}}$ are the (non-negative) relative weights assigned to the corresponding functions (radius, 1 ; tangent, 2 ; curvature, 3 ), with $\omega_{x_{1}}+\omega_{x_{2}}+\omega_{x_{3}}=1$. They are introduced in order to adjust the relative importance of the various 
representations in the definition of "similarity". The weights provide us with the freedom to emphasize finer details as we proceed with the hierarchically clustering of a complex assemblage (see below).

The definition of $d(\alpha, \beta)$ provides us with a single number that quantifies the distance between any pair of profiles. The dependence of the distance on the weighting function $\Omega(\mathrm{s})$, and on the weights $\omega_{x_{1}}, \omega_{x_{2}}, \omega_{x_{3}}$ enable the archaeologist to introduce his/her judgment and preferences in the clustering algorithm, and test them by comparing classifications which are carried out with different choices of the parameters.

The bottom line is that the distance function compares the matching sections along the two profiles and summarizes their similarity with one positive number. The distance value is 0 if and only if the two profiles are identical, the higher it is the worse is the correlation between the profiles. Given an assemblage, a convenient framework for expressing all of its inner comparisons is with a symmetric distance matrix, which will be discussed in detail below. The indices of the rows and columns of the matrix correspond to the profiles of the assemblage. Its main diagonal consists of the value 0 which correspond to the self-difference of each profile.

This matrix is always updated in the back of the database whenever new ceramic data is added. There are several statistical tools that can manipulate distance matrices and reveal inner structures and grouping. First of all, to avoid redundancies and to reduce the amount of variables, we employ PCA (Jackson 1991; Jolliffe 2002). This method transfers the original information from the distance matrix into a new matrix, with no loss of information and with independent new columns that have descending magnitude of variability. Only a few columns now suffice to represent most of the variability that exist in the assemblage and to expose the most statistically relevant attributes for classification. Second, in order to comprehensively reveal the full structure of the similarities within the assemblage, the PCA parameters have to be further manipulated. The most common and useful method is cluster analysis. This technique is a way to investigate grouping in the data, simultaneously over various scales, by creating a cluster tree. The cluster tree is a very convenient mode to explore and illustrate connections that are based on resemblance. In this tree, similar objects are placed on one branch (cluster) and each branch represents a segregated group; clusters at one level of correlation are joined at the next higher level. The various leaves are connected to a branch which by itself is also connected to a higher branch and so on, until the top of the tree (Karasik and Smilansky 2011).

We base the typology on the structure of the cluster tree: a branch on the tree corresponds to a similarity criterion, and as more bifurcations exist on the branch, the similarity criterion is more distinctive and the classification it induces is more refined. Moreover, at each step, we tune the weights by which the next branch is classified, and consider more the fine details as represented by the distance function of the tangent and the curvature functions and less the radius function. Moreover, the numeric description of the profiles enables their convenient partition into sections that can be used separately in the comparison and the analysis. For instance, if one wishes to focus the classification only on the inclination of the rim, then the distance function can take into account only the relevant parts without any bias. This is done using the weight $\Omega(\mathrm{s})$ that was described above. Tuning the weights of the profile representations $\omega_{x_{1}}, \omega_{x_{2}}, \omega_{x_{3}}$ and selecting the relevant sections for a specific 
question, are constraints which should be defined by the users. It is important to note that the ability to modify these weights do not influence the objectivity of the search. Simply because any search is repeatable and scholars who will use the same parameters will always get to the same results. It is reasonable that different archaeological questions would need different set of weights. Therefore, our method provides a very consistent way to create and apply a particular kind of typology that could be useful in particular research circumstances. However, it can also be done automatically for several sets of parameters that cover the most common attributes in ceramic assemblages. In this way, the PIQD does not require tuning of weights at every run but rather has several prerun matrices that the user is able to choose between based upon the focus of their study.

The mathematically computed ceramic typology is converted into a five-digit type code that is then linked to each corresponding sherd in the PIQD. The combination of a sherd's type code with its metadata (provenience information, context of preservation, relative dating, fabric information, and surface treatment), enable multivariate studies to be conducted that take advantage of each sherds computed placement within the overall typology. Each type code can be parsed into several nested groupings representing the different levels of the computed cluster tree (see "Case Study: Iron Age example from Edom, Southern Jordan" section; case study below for further discussion of the type code). The user can navigate through the various cluster levels of a type code to narrow down the matches of a particular sherd to other sherds found to be similar within the typology. All of the other various properties stored in the database not associated with morphology can be used as limiters to focus the query towards other specific patterns the researcher is interested in investigating. For example, a vessel's period, fabric, or geographic location can be used to narrow the search and focus on only the sherds that match these selected attribute features. As more attribute features are added, the constraints limit possible matches until the diagnostic sherds with the highest similarity are isolated. The web interface provides full control over the query system, enabling queries to be constructed that not only test typological hypotheses but also investigate patterns of artifact production, distribution, and consumption.

This mathematically based classification system provides the main advantage of the PIQD over previous methods and online analytical ceramic tools. It allows the users to run and test their own queries for morphological parallels independently of how the vessels were defined in the various published reports. The PIQD adapts to the user input to give more accurate results based on the scale of the query (i.e., a search within a single site or a search across a whole region). At the core of the PIQD is a mathematically proven and objective method (Karasik and Smilansky 2011) for ceramic classification making it more than a simple online database but a scientific tool for projects to conduct ongoing research.

\section{Case Study: Iron Age example from Edom, Southern Jordan}

\section{Introduction}

In this case study, we present a demonstration of the analytical capabilities of the PIQD in handling large datasets of 3D scans and digitized 2D ceramic profiles $(n=$ 
2,789 sherds). With the PIQD, it is possible to generate novel scientific inferences from the data without significant intervention beyond uploading the data to the PIQD. There are no optimal weights for automatic clustering and those selected depend on the purpose of the query. Here, we present several different weight scenarios to show how they affect the clustering of the data. This study aims to document how the PIQD can compare a large dataset of ceramic assemblages across the southern region of Ancient Edom.

The primary datasets that will be used are the 2D digitized ceramic profiles from published sites in the region of Edom and a 3D scanned dataset from recent excavations. In 2008, 3D scanning began of ceramic assemblages from six Iron Age II (ca. 1000-500 BCE) excavations conducted by the UCSD ELRAP and L2HE projects in the lowlands (Khirbat en-Nahas and Rujm Hamra Ifdan) and highlands (Khirbat al-Malayqtah, Khirbat al-Kur, Khirbat al-Iraq Shmaliyeh, and Tawilan) of Edom in southern Jordan (Fig. 7). All diagnostic sherds recorded in the field had their metadata inputted into the PIQD and scanned sherds were converted to a digital format with their extracted proper stance, rim diameter, and profile. The resulting data was then combined with the $2 \mathrm{D}$ digitized profiles from published ceramic assemblages of 11 neighboring Iron Age II sites.

The ceramic data assembled for this chapter enables a comparison to be drawn of the ceramics of Iron Age II (ca. 1000-500 BCE) Edom from both the lowlands and highlands of the "Edomite" region and its neighbors over time and space. The total number of 3D scanned sherds (299) have then been combined with the greater 2D scanned data, totaling 2,789 sherds from 17 sites and two surveys (c.f. Table 1). Unlike many of the "classic" Iron Age sites in Israel/Palestine, sites in Transjordan Edom have generally been poor in the preservation of complete vessels and the new ELRAP and L2HE excavations are no exception to this (cf. Hart 1989; Oakeshott 1978). ${ }^{7}$ Therefore, the morphological determinations of vessel types presented in this study rely primarily on pottery rim form and assumed curvature of vessel bodies. In the following section, we discuss the results of the automatic classification of the full dataset and present several examples of the classified groups generated.

\section{Discussion of the PIQD Cluster Analyses}

One of the advantages of the PIQD is the users' freedom to adjust the search parameters according to their own research goal and agenda. In our experience, with testing many different weights on the three functions (radius, tangent, and curvature) on this large dataset we found the tangent function most suitable for type differentiation. It stores, in the most concise way, the shape of the crosssection profiles independent of its size and without the very fine details of the curvature function. A combination of the tangent and the radius function reveals a classification that adequately separates vessel shapes and sizes. Adding greater weight to the curvature function at the final steps of the

\footnotetext{
$\overline{7}$ The one exception is KIS, which had a high level of preservation with nearly complete reconstructible vessels.
} 


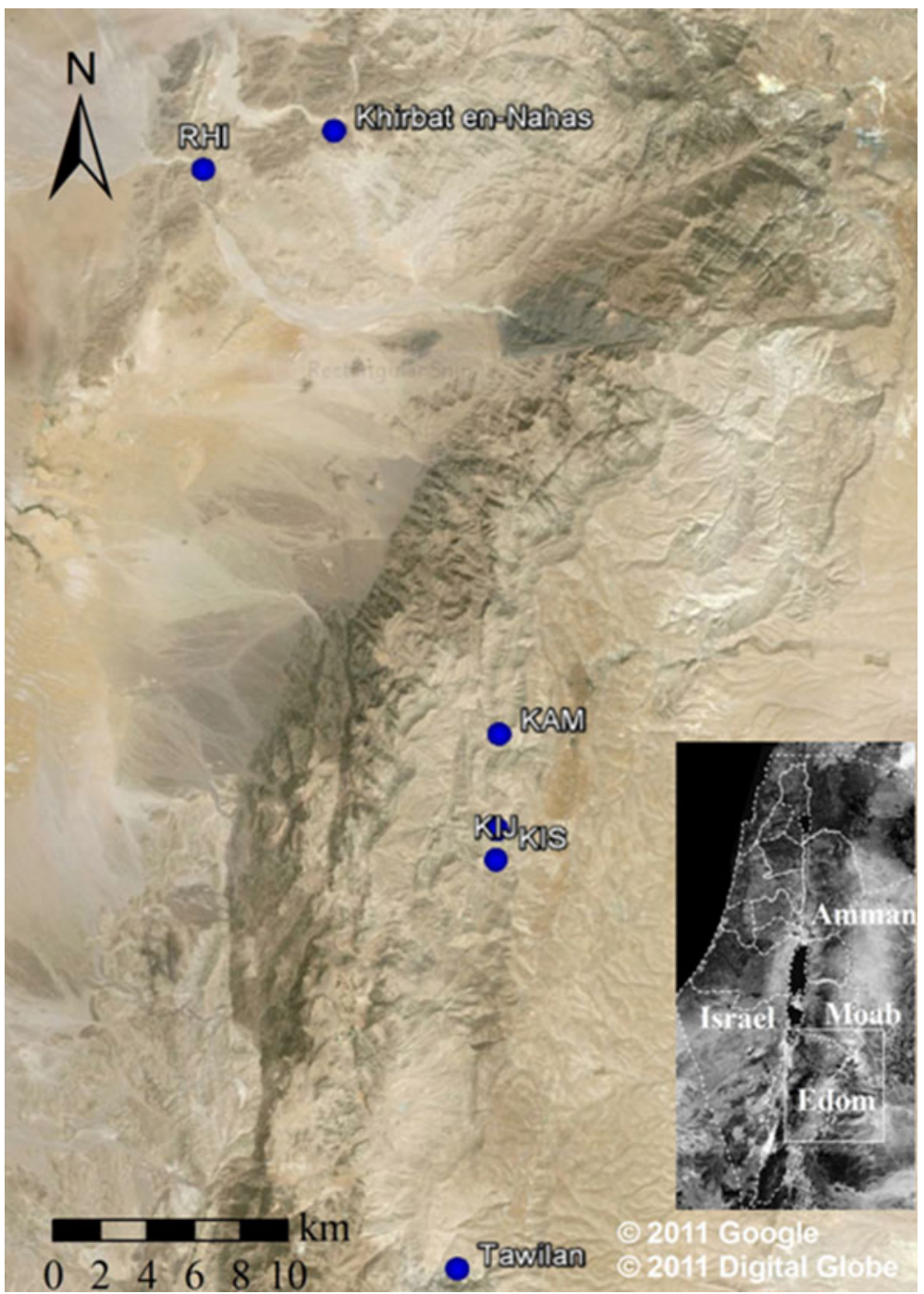

Fig. 7 Plot of sites used in study with 3D scanned pottery in google earth

classification (after the main groups have already been separated) results in the best differentiation between the subtypes. However, it is recommended to use more than one function at every step of the classification, and even at the final level of subdivisions we get better results if we keep the weight of the tangent function in the range of 30-70\%. Still, we found for the Iron Age, but no doubt many other periods, that the forms of ceramic sherds recovered from the archaeological sites is very rich and varied. There are many unique or incomplete shapes that can be defined more as outliers than as belonging to a certain type. In most cases, these outliers will end up in a separated group, but in some cases they may be grouped with a larger subtype with which they share some common parameters. Therefore, running the automatic classification on 
Table 1 Count of diagnostic rim profiles from sites in the Southern Levant used in case study

\begin{tabular}{|c|c|c|c|c|c|}
\hline Site & Season & References & Type & Abbreviation & Count \\
\hline Ash Shorabat & & Bienkowski and Adams (1999) & $2 \mathrm{D}$ scan & AshShorabat & 50 \\
\hline Baja III & & Lindner and Farajat (1987) & $2 \mathrm{D}$ scan & Baja3 & 20 \\
\hline Busayra & & Bienkowski (2002) & $2 \mathrm{D}$ scan & Busayra & 898 \\
\hline Es-Sadeh & 1988 & Lindner et al. (1988) & $2 \mathrm{D}$ scan & Es-Sadeh1 & 32 \\
\hline Es-Sadeh & 1990 & Lindner et al. (1990) & $2 \mathrm{D}$ scan & Es-Sadeh2 & 46 \\
\hline Faynan Busayra Road Survey & 2007 & & $2 \mathrm{D}$ scan & FBRS07 & 31 \\
\hline Tall Hesbon & & Ray (2001) & $2 \mathrm{D}$ scan & & 132 \\
\hline Jabal Qseir & 1996 & Lindner et al. (1996) & $2 \mathrm{D}$ scan & JabalQseir & 40 \\
\hline Kadesh Barnea & 1976-1982 & Cohen et al. (2007) & $2 \mathrm{~d}$ scan & Kadesh Barnea & 335 \\
\hline Khirbat al-Malayqtah & 2007 & Smith (2009) & $3 \mathrm{D}$ scan & KAM07 & 32 \\
\hline Khirbat en-Nahas & 2002 & Smith and Levy (2009) & $2 \mathrm{D}$ scan & KEN02 & 211 \\
\hline Khirbat en-Nahas & 2002 & Smith and Levy (2009) & $3 \mathrm{D}$ scan & KEN02 & 22 \\
\hline Khirbat en-Nahas & 2006 & Smith and Levy (2009) & 2D scan & KEN06 & 180 \\
\hline Khirbat en-Nahas & 2006 & Smith and Levy (2009) & $3 \mathrm{D}$ scan & KEN06 & 66 \\
\hline Khirbat al-Iraq Shmaliyeh & 2007 & Smith (2009) & $3 \mathrm{D}$ scan & KIJ07 & 19 \\
\hline Rujm Hamrat Ifdan & 2004 & Smith 2009 & $3 \mathrm{D}$ scan & RHI04 & 91 \\
\hline Rujm Hamrat Ifdan & 2004 & Smith (2009) & $2 \mathrm{D}$ scan & RHI04 & 27 \\
\hline Tall Jawa & & Daviau (2002) & $2 \mathrm{D}$ scan & TallJawa & 40 \\
\hline Tell Kheleifeh & & Pratico (1993) & $2 \mathrm{D}$ scan & TelKheleifeh & 252 \\
\hline Tawilan & & Hart (1995) & $2 \mathrm{D}$ scan & Tawilan & 118 \\
\hline Tawilan & 2007 & Smith (2009) & 3D Scan & TW07 & 41 \\
\hline Tel al-Muallaq & 1996 & Lindner et al. (1996) & 2D Scan & TelaMuallaq & 36 \\
\hline Umm al-Biyara & & Hart (1989) & 2D Scan & UmmAlBiyara & 32 \\
\hline Wadi al-Jariyeh Survey & 2007 & & 2D Scan & WAJ07 & 16 \\
\hline Total & & & & & 2,789 \\
\hline
\end{tabular}

assemblages that include all objects in the database may show together with the relevant results, also some irrelevant ones. Nevertheless, we found that even the untrained eye can notice and ignore these outliers. It is the approach of the PIQD to conduct a broader search with some obvious irrelevant results that can be dropped by the user as they narrow their search parameters or conduct a more refined classification on only that subtype (see example 2 for a demonstration of this).

The test case that is presented here includes 2,789 fragments from 2D scanned images and 3D models (see Table 1). Figure 8 shows an example of a cluster tree for the complete PIQD ceramic assemblage. Each branch at the bottom of the tree represents a group of similar fragments. The numbers below the tree correspond to the size of the branches. Some branches have more than 100 fragments while others have less than 20 . In order to have a comprehensive figure, the cluster tree shows only 40 branches which match the most uniform groups in the dataset.

Even before analyzing the classification, the resulting cluster tree serves as a convenient tool to detect outliers and documentation problems. For instance, the 


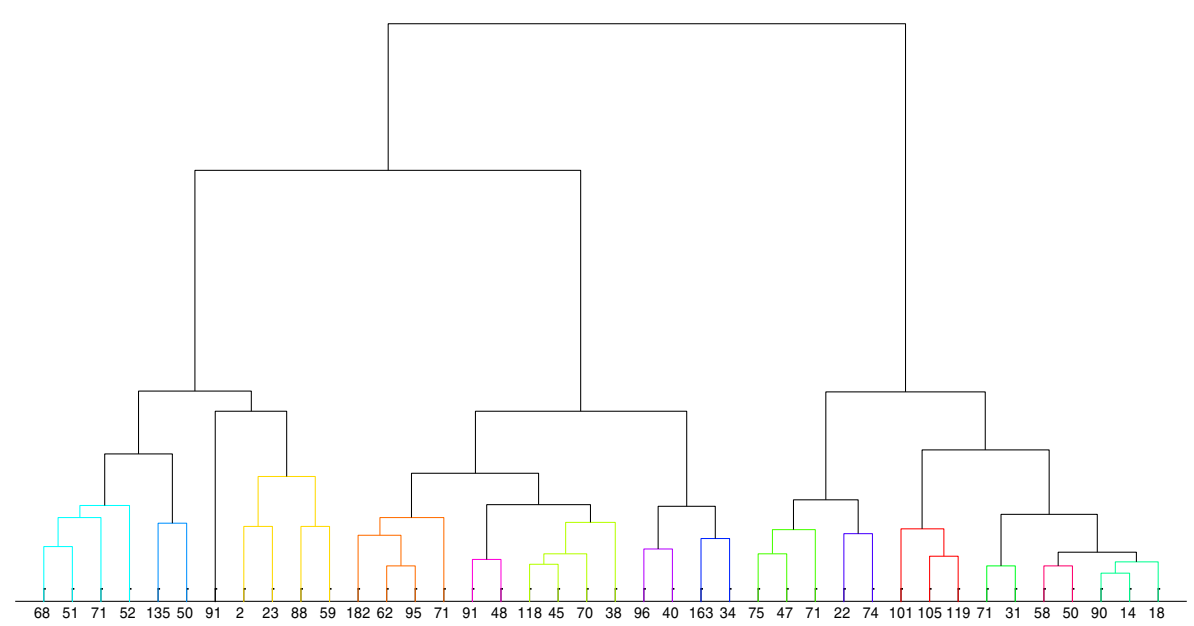

Fig. 8 A cluster tree with 40 groups for the 2,789 fragments from the Iron Age II in Edom (southern Jordan)

eighth branch from the left has only two fragments on it, which is a very low number in comparison to the rest of the tree. It is possible that there are two unique vessels which are very different from the rest of the assemblage. However, a deeper look on these two vessels proved that they were incorrectly digitized. Their starting point was defined at the middle of the profiles instead of at the bottom of the fragments. This kind of mistake derived from an improper preparation of the scanned drawing. Therefore, the classification's outliers can serve as another check on the quality of the data that is inputted in the database. These mistakes can then be addressed and the data updated.

As was mentioned before and published elsewhere (Karasik and Smilansky 2011), the construction of the tree is done in several steps. At the first step, the complete assemblage is divided into the main branches according to the predefined set of weights. In the following levels, each of the branches is treated as a separate group and further divided according to the weights of the present level. In the analysis of the current assemblage, we used five division levels. At each level, the number of subdivisions is limited to the range of 2-9 and the corresponding branches are numbered with indices of 1-9. If the group is smaller than a predetermined size, the index of the group at this level is set to 0 . When the clustering is complete, every branch that was defined as a separated subtype has a type code number with five digits that correspond to the indices at each of the five division levels. The digits of that type code match the subdivision index at each step (Karasik and Smilansky 2011). The search for parallels is based on the type codes. Similar objects would have the same final type code, and one can always broaden the search by ignoring the last digit to examine several groups at a time (see example 3 for a demonstration of this).

In the remaining portion of this section, we shall demonstrate the capability of the computed typological classification and its shortcoming by discussing in greater detail four test examples from the cluster tree and how they are affected by different sets of weights or more detailed classification. 
Example 1: (type code 32330, $5 ; n=30)^{89}$

The bowl group presented in Fig. 9 was autogenerated using the default weights generated whenever new sherds were added to the PIQD. ${ }^{10}$ This is an ideal example of the automated classification (Fig. 9). Ten sites from the entire database were found to contain parallel vessel types. This example also demonstrates the ability to combine 3D scanned sherds with 2D illustrations. The sherds from KAM, KIS, KIJ, TW, and RHI were all derived from 3D scans, while Busayra, Tawilan, Tel alKheleifeh, FBRS, and one example from RHI (RHI04_101v) were derived from 2D illustrations. Note that this type has a very standardized rim diameter, stance, and profile. It was these factors that led to such a high correlation using the weights applied. There is still a level of variation in profile curvature especially seen with the last row of figures. These large globular bowls with high carination are a typical form found at various sites in Edom but relatively rare outside of the region. They were first classified by Oakeshott (1978) as "Type N" bowls and have continued to be considered a distinct group belonging to "Edomite" ceramic styles by other ceramic specialists (c.f. Hart 1995; Smith and Levy 2009). This example demonstrates that the PIQD classification system is able to generate equivalent typological results based on a purely mathematical approach.

Example 2: (type code 25210, $n=36 ; 33124, n=80$ )

An important feature of the PIQD is the ability for the user to conduct a more refined classification of a generated subtype (Figs. 10 and 11). This is important to help identify local production processes and possible exchange mechanisms with other sites. In Figs. 10 and 11 below, it was noticed that for both grouping at the fifth level (type code 25210 and 33124) very different looking classes of bowl were lumped together by the automatic classification. Therefore, a sixth level of classification placing a greater ratio to the curvature function was ran only on this group to further differentiate the different types automatically placed in this grouping. The figures above represent the automatic results if a sixth level of classification is used. ${ }^{11}$

As can be seen on the bottom five rows of Fig. 11, the globular bowls, similar to those grouped in Fig. 10 but with a sharper carination and straight rim rather than

\footnotetext{
${ }^{8}$ See Fig. 8, branch 5. curvature) used for each level are:

Level $1-20,80$, and $0 \%$

Level 2-20, 80, $0 \%$

Level 3-30, 50, $20 \%$

Level $4-20,50,30 \%$

Level $5-0,60,40 \%$.

11 The weights used for the sixth level of classification are: $0,70,30 \%$.
}

${ }^{9}$ All figures presented here are autogenerated digital forms derived from MATLAB functions discussed above. These were vectorized and imported into MATLAB from their original 2D illustration or 3D scans and are currently stored in the PIQD. The naming system below each figure refers to the site it originates from and where available the figure's bibliographic reference or registration number. Illustration of the decoration and burnishing, especially common for bowls in Figure 9, are not displayed here.

${ }^{10}$ By weights, we refer to the ratio between the radius, tangent, and curvature functions used to create the ceramic classification at each level of the type code. The default weights in percentage (radius, tangent, 

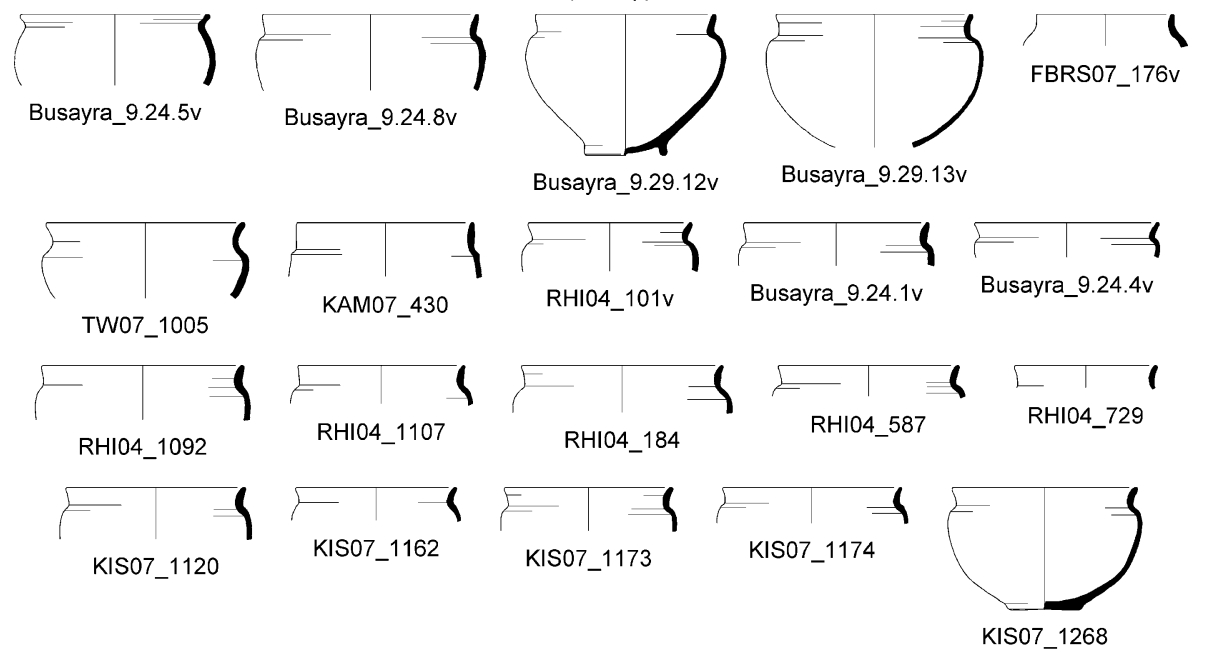

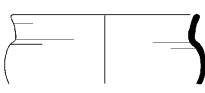

KAM07_104

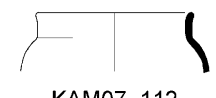

KAM07_112

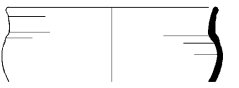

TelKheleifeh_27.17v

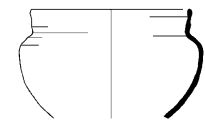

TelKheleifeh_28.3v

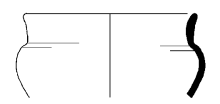

KAM07_265
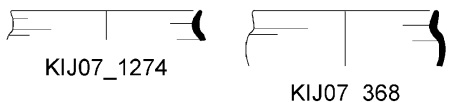

KIJ07_368
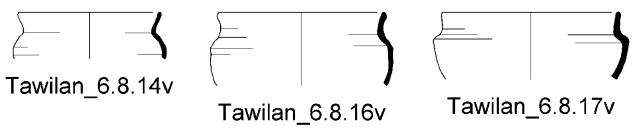

Fig. 9 Iron Age II bowls classified into type code 32330

sloping out, are now automatically differentiated from the first two rows of deep globular bowls that lack carination. It is noticeable that in the first two rows that this morphological grouping would need to be refined even further with a greater emphasis on the full profile of the sherds since it consists of crude hand-made bowls and fine thin walled bowls with some witnessing ring bases (e.g., Busayra 9.36.7, Busayra 9.58.9, Busayra 9.45.9). The differentiation of the two top rows could also be more simply separated using the PIQD by limiting the query to manufacture type of either hand- or wheel-made pottery.

In Figure 11, a sixth level of classification resulted in three groups distinguished within the subtype. Group A contains the bowls possessing an inverted rim associated with beveled rim bowls of Oakeshott (1978: type D), while group B consists of bowls in all respects very similar but have less inverted rims and typically a ridge below, and group $\mathrm{C}$ which is more heterogeneous containing bowls with rim's either everted or less triangular and more rounded. Another intriguing aspect of this classification is that the morphological differences in the rims also show a significant distributional pattern of where these bowls originated. Group A primarily comes from the later Iron II sites in the lowlands and highlands of Edom, group B primarily from the Early Iron IIA Khirbat en-Nahas, and group B from sites on the edges or outside of known Edomite territory. 

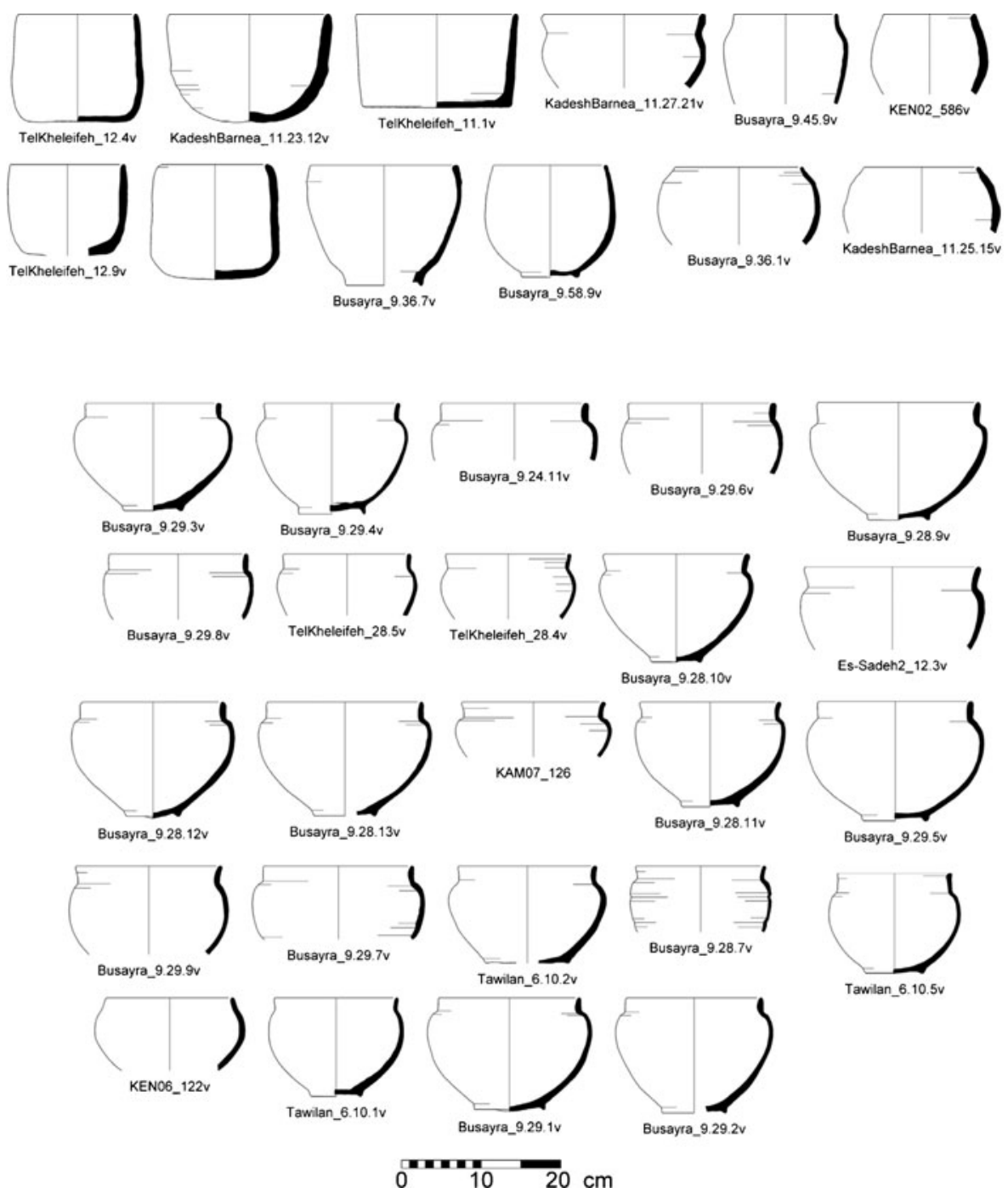

Fig. 10 Iron Age II bowls from type-code 25210 further classified into two distinct groups

Example 3: (type-codes 22213, $n=24 ; 22212, n=19 ; 22211, n=13)^{12}$

As discussed above, the initial weights used for the three mathematical functions can play a role in how type code groups are generated (Fig. 12). With the PIQD, it is possible to not only look at the level 5 grouping but to go up a branch to see how several groups are associated together. Figure 12 plots three groups (type codes 22213, 22212, 22211) belonging to the same branch (23rd from the left on Fig. 8). Group A represents a very homogenous group of ridged rim jugs. As is

\footnotetext{
${ }^{12}$ Note that for Fig. 12, only the digital profiles of these jugs are plotted here. Many of the examples in their original illustration had strap handles attached. The sample presented in Fig. 12 is only a representative sample see "Example 3" header for full count of each group.
} 


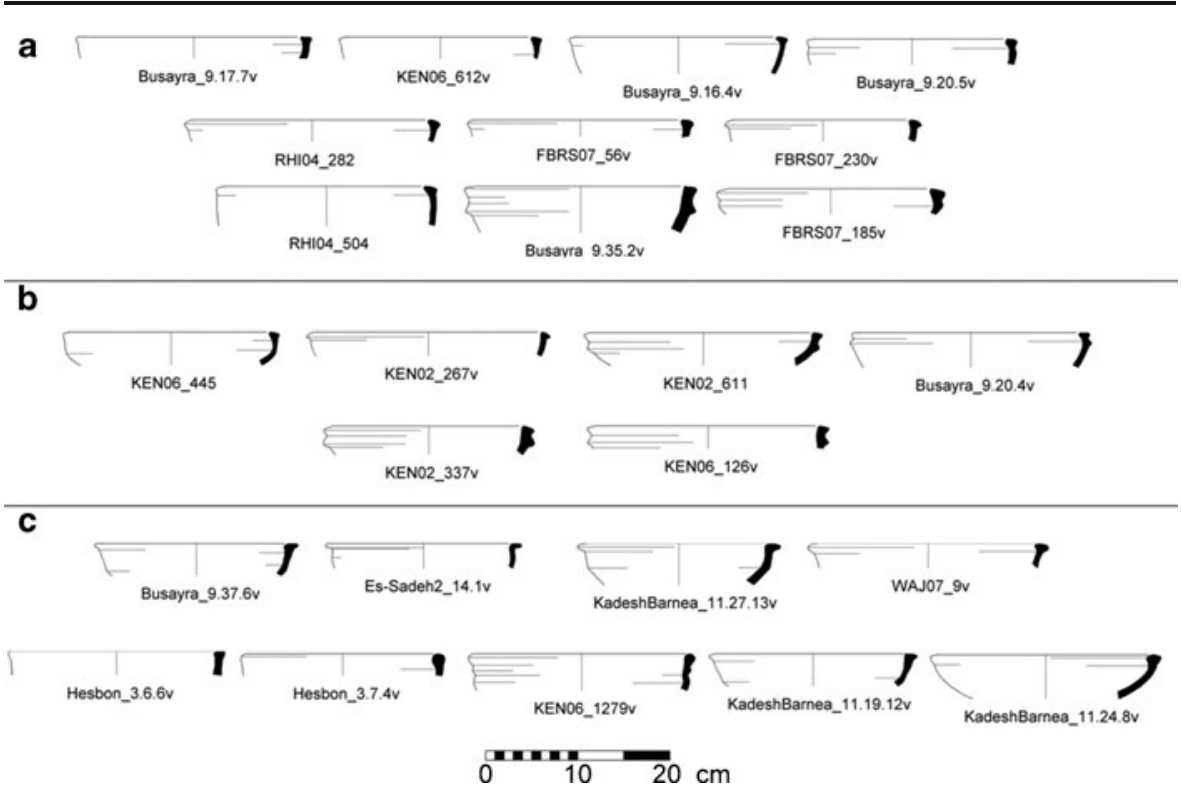

Fig. 11 Iron Age II bowls from type-code 33124 further classified into three distinct groups

exampled here, it is a common form found in Transjordan but also Israel/ Palestine and in general variations of this type are found throughout the entire Iron II period (c.f. Smith and Levy 2009). Group B appears to be primarily grouped according to the vertical stance of the rim and simple rim treatment. In Group B, there are several examples that should be considered outliers such as KEN02_899 which is a bowl, Busayra 9.58.8 which has a much wider orifice in ratio to its walls, it would typically be classified as a cooking jug (see Smith 2009), and Ash-Shorabat 1.2 which is a different jug altogether. In general, although the rim diameters and treatments are similar, the body shapes differ significantly. In group $\mathrm{C}$, the three figures, Kadesh Barnea 11.23.5, Busayra 9.58.1, and Es-Sadeh2 10.6, share very similar necks and rim treatment, but the overall body shape and size are different and it is questionable how similar Kadesh Barnea 11.23.5 is to the other two. Kadesh Barnea 11.3.6 does not fit well with this group and although found within the same branch as group B, would have more appropriately belonged to this group rather than group C. Tall Jawa 12.6.2 is a more unique form and thus may have been selected for this group because it shared only some common parameters.

We have tested the influence of the various sets of weights on these three subtypes. After running a different set of weights emphasizing the curvature function, only two sherds were removed from the group and classified in another (AshShorabat 1.9 and Busayra 9.54.11). Their removal fits with the typology since they lacked the dominant parameters of the main type plotted in the group. Three sherds were added to group A from group C (Es-Sadeh 2 10.6, Busayra 9.58.1, Kadesh Barnea 11.23.5); these three figures were noted above to go well together but not fit with the rest of the group $\mathrm{C}$ because of their rim. Their new inclusion into group $\mathrm{A}$ due to a higher weight on the curvature function makes sense. However, two sherds from group B 

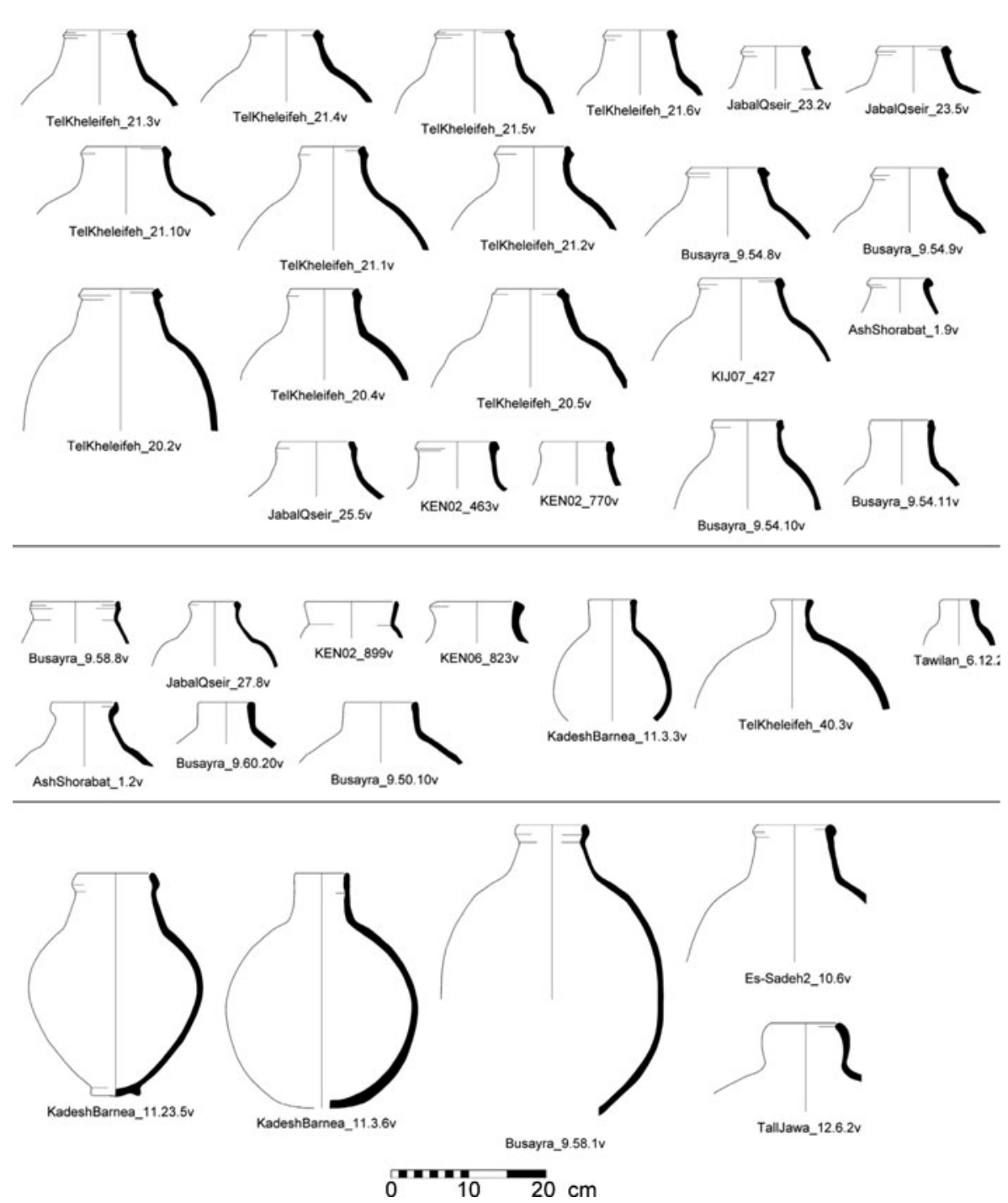

Fig. 12 Iron Age II Jugs at the fourth level of classification using default weight ratios (type codes: group A, 22213; group B, 22212; group C, 22211)

(KEN06_823 and Busayra 9.50.10) moved to group A but are of the simple rim form; in this case, the new weights produced worse results. Overall, group A gained 20 more vessels, suggesting that the changing of the weights made it more inclusive of jugs originally differentiated into other groups. The group included more ridged rims but it also contained more outliers and sherds not as closely related to the core type. The different analyses show that the changing of the weights has minimal effect on the core types of a group that share many parameters, but will generally move vessels on the borders of a type that possess only a few similar parameters. This is a disadvantage of using a hierarchical system of cluster analysis (c.f. Karasik and Smilansky, 2011). 
Example 4: (type code 21320, $n=19)$

In the final example, type code 21320 represents a clearly defined group of cooking pots (Fig. 13). This specific closed vessel form with a ridged rim is very typical for cooking pots in the Iron Age II southern Levant (c.f. Smith 2009). These cooking pots can not only be distinguished by their rim but also fabric and manufacture, which is often vitrified and brittle from its high firing, contain inclusions beneficial for firing (e.g., calcite) and are constructed from a mold or coiling technique rather than being spun on a wheel. The vessel walls are thin and porous allowing the vessel to breathe and expand during cooking. Often, these cooking pots are coated with black soot from the fire they were either placed in or hung over. Nine sites were found to have similar cooking pot forms in this type code. As can be seen in Fig. 13, there are two outliers (Busayra 9.35.13 and FBRS07_54) and every ridged rim is folded differently. Nevertheless, their clustering in this group makes sense looking at the global stance of the fragments and the dominant features near the rim.

In order to investigate if a greater weight towards the curvature function would affect how the cooking pots were grouped at the fifth level, we ran a second classification. What we found was contrary to what we expected; there was a greater range in the groups containing both cooking pots and holemouth jars (vessels with very similar profile to cooking pots but having a simple rounded rim rather than thickened ridged rim). The distinct group (21320) of cooking pots was now divided primarily into three groups that also contained holemouth jars and other jars with a large diameter. The results suggest that it is primarily the tangent function that plays the greatest role in properly differentiating ceramics according to parameters and at

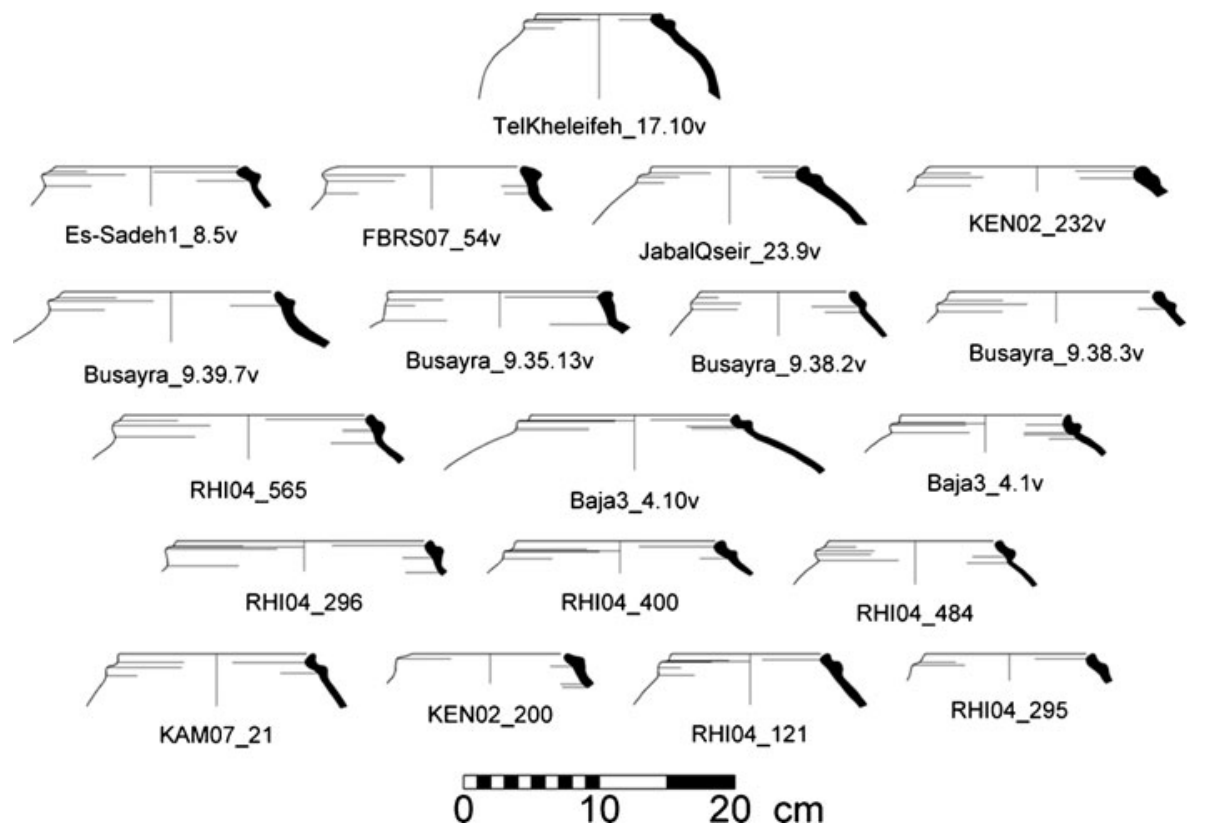

Fig. 13 Iron Age II cooking pots (type code, 21320) 
this level of abstraction the increase of the curvature function's weight causes greater inclusion of different types. Using a higher curvature function, weight only becomes significant where a greater resolution of classification is needed within a preselected subtype as was demonstrated in example 2 and published elsewhere (Adan-Bayewitz et al. 2009).

To sum up the examples of the classification demonstrated above, we can say that the integration of a large digital ceramic database together with advanced methods of comparison and the computational power of modern computers has great potential for ceramic analysis. Not only does this method save time and efforts for the never-ending task of searching for ceramic parallels in old publications, but it can also serve as an important research tool. The ability to access the PIQD from anywhere in the world and to compare your data against what is already known, while playing with the parameters of the classification, opens the opportunity to ask more questions in regards to the various parallels in the database. Moreover, the objectivity of the method, its repeatability and its digital nature make the complete procedure of pottery analysis more transparent to other scholars and therefore improve our discipline.

\section{Summary}

The Pottery Informatics Query Database will help enable archaeologists to conduct the kind of BLAST searches that have become common in the biological sciences. In the future, researchers will be able to compare ceramics across thousands of sites with a click of the button. In addition, the various integrated tools will enable a sophisticated management of one's data and ensure quality control throughout. Since the PIQD is online (http://adaa.ucsd.edu/PIQD) and built around web-based programming languages, it has a great deal of room to expand in both allowing new data to be integrated and new tools to be developed. The PIQD is designed to be a critical resource in the digital age of cyber-archaeology. This tool has already been essential to a number of publications for the creation of publishable plates, tables, and a number of analyses. As shown in the case study presented here, any user can conduct a number of complex analyses using the PIQD. By providing researchers with a rich analytical database that includes comprehensive metadata for the PIQD, as well as digital conversions of published ceramic illustrations and their metadata from the majority of the most significant Iron Age southern Levant excavations, it is hoped that a new revolution in how regional ceramic analyses are conducted is kick-started here. It is our hope that as more researchers become involved, collaboration and novel research can be initiated through the PIQD that is currently impossible.

Acknowledgments We are grateful to Professor Ramesh Rao, Director, California Institute of Telecommunications and Information Technology (Calit2), San Diego Division, UCSD, for his long-term support of this project. The research provides a platform for our graduate students involved in the UCSD Center of Interdisciplinary Science for Art, Architecture and Archaeology (CISA3)/Calit2 NSF IGERT TEECH grant. Fieldwork was facilitated by grants from the National Geographic Society, NSF, the UCSD Judaic Studies Program, and private donors. We also would like to acknowledge Kristiana Smith, Brian 
Tipton, Sorayda Santos, Charlene Wang, Caity Connoll and Ahmad Hasanat for their many hours spent conducting database entry and digitization of the ceramic datasets presented in this paper.

\section{References}

Adams, W. Y., \& Adams, E. W. (1991). Archaeological typology and practical reality: a dialectical approach to artifact classification and sorting. Cambridge: Cambridge University Press.

Adan-Bayewitz, D., Karasik, A., Smilansky, U., Asaro, F., Giauque, R. D., \& Lavidor, R. (2009). Differentiation of ceramic chemical element composition and vessel morphology at a pottery production center in Roman Galilee. Journal of Archaeological Science, 36(11), 2517-2530.

Adler, K., Kampel, M., Kastler, R., Penz, M., Sablatnig, R., Schindler, K. and Tosovic, S. (2001) Computer aided classification of ceramics - achievements and problems. Proc. of 6th Intl. Workshop on Archaeology and Computers. Vienna, Austria.

Altschul, S. F., Gish, W., Miller, W., Myers, E. W., \& Lipman, D. J. (1990). Basic local alignment search tool. Journal of Molecular Biology, 215(3), 403-410.

Amiran, R. (1969). Ancient pottery of the Holy Land. Jerusalem: Israel Exploration Society.

Arnold, D. E. (1985). Ceramic theory and cultural process. New studies in archaeology. Cambridge: Cambridge University Press.

Arnold, D. E. (1989). Patterns of learning, residence and descent among potters in Ticul, Yucatan, Mexico. In S. J. Shennan (Ed.), Archaeological approaches to cultural identity, one world archaeology (pp. 174-184). London: Unwin Hyman.

Artzy, M. (1994). Incense, camels and collared-rim jars: desert trade routes and maritime outlets in the second millennium. Oxford Journal of Archaeology, 13, 121-147.

Banning, E. B. (2000). The archaeologist's laboratory: the analysis of archaeological data. New York: Kluwer.

Bienkowski, P. (1992). Early Edom and Moab - the beginning of the Iron Age in Southern Jordan. Sheffield Archaeological Monographs 7. Sheffield: Collis.

Bienkowski, P. (2002). Busayra excavations by Crystal M. Bennett, 1971-1980. British Academy Monographs In archaeology; no. 13. Council for British Research in the Levant. Oxford: Oxford University Press.

Bienkowski, P., \& Adams, R. B. (1999). Soundings at Ash-Shorbat and Khirbet Dubab in the Wadi Hasa. Levant, 31, 149-72.

Bienkowski, P., \& van der Steen, E. (2001). Tribes, trade, and towns: a new framework for the Late Iron age in Southern Jordan and the Negev. Bulletin of the American Schools of Oriental Research, 323, 21-47.

Bishop G., Chas-H., Tappert C. 2005. A Greek pottery shape and school identification and classification system using image retrieval techniques. Proceedings of Student/Faculty Research Day CSIS, Pace University.

Cohen, R., H. Bernick-Greenberg, D. B.-Y. Mayer, and H.-A. Israel Rashut (2007) Excavations at Kadesh Barnea (Tell el-Qudeirat) 1976-1982. IAA Reports, no. 34/1-34/2. Jerusalem: Israel Antiquities Authority.

Daviau, M. P. (2002). Excavations at Tall Jawa, Jordan. Boston: Brill.

Deal, M. (2007). An ethnoarchaeological perspective on local ceramic production and distribution in the Maya Haghlands. In C. A. Pool \& G. J. Bey (Eds.), Pottery economics in mesoamerica (pp. 39-58). Tucson: The University of Arizona Press.

Dever, W. G. (1993). Cultural continuity, ethnicity in the archaeological record, and the question of Israelite origins. Eretz Israel, 24, 22-33.

Dever, W. G. (2003). Who were the early Israelites, and where did they come from? Grand Rapids: Eerdmans.

Dietler, M., \& Herbich, I. (1998). Habitus, techniques, style: an integrated approach to the social understanding of material culture and boundaries. In M. T. Stark (Ed.), The Archaeology of social boundaries (pp. 232-263). Washington: Smithsonian Institution.

Dornemann, R. H. (1983). The archaeology of the transjordan in the Bronze and Iron Ages. Milwaukee: Milwaukee Public Museum.

Dunnell, R. C. (1971). Systematics in prehistory. New York: The Free Press.

Durham, P., Lewis, P., \& Shennan, S. (1995). Artefact matching and retrieval using the generalised hough transform. Computer Applications and Quantitative Methods in Archaeology, 1993(1995), 25-30.

Edelman, D. V. (2002). Ethnicity and early Israel. In M. G. Brett (Ed.), Ethnicity and the Bible (pp. 25-55). Leiden: E.J. Brill. 
Faust, A. (2006). Israel's ethnogenesis: settlement, interaction, expansion and resistance. London: Equinox Pub.

Finkelstein, I. 1992. Edom in the Iron I. Levant XXIV:159-166.

Finkelstein, I. (1997). Pots and people revisited: ethnic boundaries in the Iron Age. In N. A. Silberman \& D. B. Small (Eds.), The archaeology of Israel: constructing the past, interpreting the present (pp. 21637). Sheffield, England: Sheffield Academic.

Finkelstein, I. (2005a). Khirbet en-Nahas, Edom and biblical history. Tel Aviv, 32(1), 119-125.

Finkelstein, I. (2005b). A low chronology update-archaeology, history and bible. In T. E. Levy TE \& T. Higham (Eds.), The bible and radiocarbon dating-archaeology, text and science (pp. 31-42). London: Equinox.

Finkelstein, I. (2011). Tall al-Umayri in the Iron Age I-facts and fiction with an appendix on the history of the Collared Rim Pithoi. In I. Finkelstein \& N. Naaman (Eds.), The fire signals of Lachish, studies in the archaeology and history of Israel in the Late Bronze Age, Iron Age, and Persian period in honor of David Ussishkin (pp. 113-127). Winona Lake: Eisenbrauns.

Finkelstein, I., \& Piasetzky, E. (2008). Radiocarbon and the history of copper production at Khirbet enNahas. Tel Aviv, 35, 82-95.

Finkelstein, I., \& Piasetzky, E. (2009). Radiocarbon-dated destruction layers: a skeleton for Iron Age chronology in the Levant. Oxford Journal of Archaeology, 28(3), 255-274.

Finkelstein, I., \& Silberman, N. A. (2006). David and Solomon-in search of the Bible's sacred kings and the roots of Western tradition. New York: Free Press.

Gero, J., \& Mazzullo, J. (1984). Analysis of artifact shape using fourier series in closed form. Journal of Field Archaeology, 11(3), 315-322.

Gifford, J. C. (1960). The type-variety method ceramic classification as an indicator of cultural phenomena. American Antiquity, 25(3), 341-47.

Gilboa, A., Karasik, A., Sharon, I., \& Smilansky, U. (2004). Towards computerized typology and classification of ceramics. Journal of Archaeological Science, 31, 681-694.

Gitin, S. (1990). Gezer III: a ceramic typology of the Late Iron II. Jerusalem: Persian and Hellenistic Periods at Tell Gezer.

Goren, Y. (1996). The southern Levant in the early Bronze Age IV: the petrographic perspective. Bulletin of the American Schools of Oriental Research, 303, 33-72.

Goren, Y., I. Finkelstein, and N. Na'aman. 2004. Inscribed in clay-provenance study of the Amarna Letters and other Ancient Near Eastern Texts. Tel Aviv: Tel Aviv University monograph series 31.

J Gunneweg, M Balla (2002) Instrumental neutron activation analysis, Busayra and Judah. In: M. Balla and P. Bienkowski (eds). Busayra: excavations by Crystal M. Bennett 1971-1980. British academy monographs in archaeology volume. Oxford: Oxford University Press. pp. 483

Gunneweg, J., Beier, T., Diehl, U., Lambrecht, D., \& Mommsen, H. (1991). 'Edomite', 'Negbite' and 'Midianite' pottery from the negev desert and Jordan: instrumental neutron activation analysis results. Archaeometry, 33, 239.

Gunneweg, J, et al. (1991) 'Edomite,' 'Negbite' and 'Midianite' pottery from the Negac desert Adn Jordan: instrumental neutron activation analysis results. Archaeometry 33.

Hagstrum, M. B., \& Hildebrand, J. A. (1990). The 'two-curvature' method for reconstructing ceramic morphology. American Antiquity, 55(2), 388-403.

Halir, R. 1999. An automatic estimation of the axis of rotation of fragments of archaeological pottery: a multi-step model-based approach. Proc. of the 7th International conference in Central Europe on computer graphics, Visualization and Interactive Digital Media (WSCG '99)

Hall, N. S., \& Laflin, S. (1984). A computer aided design technique for pottery profiles. In S. Laflin (Ed.), Computer applications in archaeology (pp. 178-88). Birmingham: Computer Centre, University of Birmingham.

Hand, D. J. (1997). Construction and assessment of classification rules. New York: Wiley.

Hart, S. 1989. The Archaeology of the land of Edom, Ph.D. thesis. Macquarie University.

Hart, S. (1995). The pottery. In C.-M. Bennett \& P. Bienkowski (Eds.), Excavations at Tawilan in Southern Jordan, British Academy monograph in archaeology (pp. 53-66). Oxford: Published for the British Institute at Amman for Archaeology and History by Oxford University Press.

Herr, L. (2001). The history of the Collared Pithos at Tell el- Umeri, Jordan. In S. R. Wolff (Ed.), Studies in the archaeology of Israel and neighboring lands (pp. 237-50). Chicago: Oriental Institute of the University of Chicago.

Jackson, J. E. (1991). A user's guide to principal components. New York: Wiley.

Jolliffe, I. T. (2002). Principal component analysis (2nd ed.). Springer: New York.

Kampel, M., \& Sablatnig, R. (2003). An automatic pottery archival and reconstruction system. The Journal of Visualization and Computer Animation, 14(3), 111-120. 
Kampel, M., H. Mara, et al. 2005. Robust 3D reconstruction of archaeological pottery based on concentric circular rills. N. Magnenat-Thalmann and J. H. Rindel (eds). Proc. of the 6th International Workshop on Image Analysis for Multimedia Interactive Services (WIAMIS'05). Montreux: Switzerland. pp 14 20 .

Karasik, A. (2008a) Applications of 3D technology as a research tool in archaeological ceramic analysis. In: B. Frischer and A. Dakouri-Hild (eds). Beyond illustration: 2D and 3D digital technology as tools for discovery in archaeology. British Archaeological Reports International Series 1805. Pp 103-116

Karasik, A. (2008b) Applications of 3D technology as a research tool in archaeological ceramic analysis. B Frischer and A Dakuri-Hild (eds.) In: Beyond illustration: $2 D$ and $3 D$ digital technology as tools for discovery in archaeology. Oxford: British Archaeological Reports International series 1805. pp. 103-116

Karasik, A. (2010) A complete, automatic procedure for pottery documentation and analysis. Computer Vision and Pattern Recognition Workshops (CVPRW), 2010 IEEE Computer Society 29-34.

Karasik, A., \& Smilansky, U. (2008). 3D scanning technology as a standard archaeological tool for pottery analysis: practice and theory. Journal of Archaeological Science, 35, 1148-1168.

Karasik, A., \& Smilansky, U. (2011). Computerized morphological classification of ceramics. Journal of Archaeological Science, 38, 2644-2657.

Karasik, A., Smilansky, U., \& Beit-Arieh, I. (2005). New typological analyses of Holemouth Jars from the early bronze age from Tel Arad and Southern Sinai. Tel-Aviv, 32, 20-31.

Knauf, E. A. (1992). The cultural impact of secondary state formation: the cases of the edomites and the moabites. In P. Bienkowski (Ed.), Early Edom and Moab: the beginning of the Iron Age in Southern Jordan (pp. 47-54). Sheffield: Collis.

LaBianca, O. S. (1999). Salient features of iron age Tribal Kingdoms. In B. MacDonald \& R. W. Younker (Eds.), Ancient Ammon, studies in the history and culture of the ancient Near East 17. Boston: Brill.

LaBianca, O. S., \& Younker, R. W. (1995a). The Kingdoms of Ammon, Moab and Edom: the archaeology of society in Late Bronze/Iron Age transjordan (ca. 1400-500 BCE). In T. E. Levy TE (Ed.), The archaeology of society in the Holy Land (pp. 399-415). London: Leicester University Press.

LaBianca, O. S., \& Younker, R. W. (1995b). The Kingdoms of Ammon, Moab and Edom: the archaeology of society in Late Bronze/Iron Age Transjordan (ca. 1400-500 BCE). In T. E. Levy (Ed.), The archaeology of society in the Holy Land (pp. 399-415). London: Leicester University Press.

Lechtman, H. (1977). Style in technology: some early thoughts. In H. Lechtman \& R. S. Merrill (Eds.), Material cultures: styles, organization, and dynamics of technology (pp. 3-20). St. Paul: West.

Leese, M. N., \& Main, P. L. (1983). An approach to the assessment of artefact dimension as descriptors of shape. In J. G. B. Haigh (Ed.), Computer applications in archaeology (pp. 171-180). Bradford: University of Bradford.

Lemonnier, P. (1986). The study of material culture today: towards an anthropology of technical systems. Journal of anthropological archaeology, 5, 147-186.

Lengyel, A (1975) Computer applications in classical archaeology. In proceedings of computer applications in archaeology. pp. 56-62.

Levy, TE (2004) Some theoretical issues concerning the rise of the Edomite Kingdom - searching for "premodern identities.". In: F. al-Khraysheh F (eds). Studies in the history and archaeology of Jordan. Amman: Department of Antiquities of Jordan. p 63-89.

Levy, T. E. (2009). Pastoral nomads and Iron Age metal production in Ancient Edom. In J. Szuchman (Ed.), Nomads, tribes, and the state in the ancient near east (pp. 147-176). Chicago: University of Chicago Press.

Levy, T. E. (2010). The new pragmatism: Integrating anthropological, digital, and historical biblical archaeologies. In T. E. Levy (Ed.), Historical biblical archaeology and the future-the new pragmatism (pp. 3-44). London: Equinox.

Levy, T. E., \& Higham, T. (Eds.). (2005). The bible and radiocarbon dating-archaeology, text and science. London: Equinox.

Levy, T. E., \& Najjar, M. (2006). Some thoughts on Khirbat en-Nahas, Edom, biblical history and anthropology - a response to Israel Finkelstein. Tel Aviv, 33, 107-122.

Levy, T. E., \& Smith, N. G. (2007). On-site digital archaeology: GIS-based excavation recording in Southern Jordan. In T. E. Levy, M. Daviau, R. Younker, \& M. Shaer (Eds.), Crossing Jordan-North American contributions to the archaeology of Jordan (pp. 47-58). London: Equinox.

Levy, T. E., Adams, R. B., Anderson, J. D., Najjar, N., Smith, N., Arbel, Y., et al. (2003). An iron age landscape in the edomite lowlands: archaeological surveys along the Wadi al-Guwayb and Wadi alJariyeh, Jabal Hamrat Fidan, Jordan, 2002. Annual of the Department of Antiquities Jordan, 47, 247277 . 
Levy, T. E., Najjar, M., van der Plicht, J., Smith, N. G., Bruins, H. J., \& Higham, T. (2005). Lowland Edom and the high and low chronologies: Edomite State Formation, the Bible and recent archaeological research in Southern Jordan. In T. E. Levy \& T. Higham (Eds.), The bible and radiocarbon datingarchaeology, text and science (pp. 129-163). London: Equinox.

Levy, T. E., T. Higham, C. Bronk-Ramsey, N. G. Smith, E. Ben Yosef, M. Robinson, S. Munger, K. Knabb, J. Schultz, M. Najjar, and L. Tauxe (2008) High precision radiocarbon dating and historical biblical archaeology in Southern Jordan. Proceedings of the National Academy of Science 43.

Levy, T. E., Petrovic, V., Wypych, T., Gidding, A., Knabb, K., Hernandez, D., et al. (2010). On-site digital archaeology 3.0 and cyber-archaeology: into the future of the past-new developments, delivery and the creation of a data avalanche. In M. Forte (Ed.), Introduction to cyber-archaeology (pp. 135-153). Oxford: Archaeopress.

Levy, T. E., Najjar, M., \& Higham, T. (2010). Ancient texts and archaeology revisited-radiocarbon and Biblical dating in the southern Levant. Antiquity, 84(325), 834-847.

Lewis, P. H., and K. J. Goodson (1991) Images, databases and edge detection for archaeological object drawings. Computer applications and quantitative methods in archaeology 1990, 1991, pp. 149-153. BAR Int. Ser. 565.

Leymarie, F., Cooper, D., Joukowsky, M. S., Kimia, B., Laidlaw, D., Mumford, D., et al. (2001). The SHAPE Lab.- New technology and software for archaeologists. In Z. Stancic \& T. Veljanovski (Eds.), Computer applications and quantitative methods in archaeology. BAR International Series 931 (pp. 79-89). Oxford: Archaeopress.

Liming, G., L. Hongjie, and J. Wilcock (1989) The analysis of ancient Chinese pottery and porcelain shapes: a study of classical profiles from the Yangshao culture to the Qing dynasty using computerized profile data reduction, cluster analysis and fuzzy boundary discrimination. Computer Applications and quantitative methods in Archaeology 1989, 1989, pp. 363-374. BAR Int. Ser. 548.

Lindner, M., \& Farajat, S. (1987). An edomite mountain stronghold North of Petra (Ba'ja III). Annual of the Department of Antiquities of Jordan, 32, 175-185.

Lindner, M., Farajat, S., \& Zeitler, J. P. (1988). Es-Sadeh: an important edomite-nabatean site in Southern Jordan-preliminary report. Annual of the Department of Antiquities Jordan, 32, 75-99.

Lindner, M., Farajat, S., \& Knauf, E. A. (1990). Es-Sadeh. A Lithic-Early Bronze-Iron II (Edomite)Nabataean site in Southern Jordan. Report on the second exploratory campaign, 1988. ADAJ, 34, 193225.

Lindner, M., E.A. Knauf, J.P. Zeitler, and H. Hube. 1996. Jabal al-Qseir: A Fortified Iron II (Edomite) Mountain Stronghold in Southern Jordan, its pottery and its historical context. Annual of the Department of Antiquities. XL:137-166.

Liu, D., Razdan, A., Simon, A., \& Bae, M. (2005). An XML-based information model for archaeological pottery. Journal of Zhejiang University. Science, 6, 447-453.

Main P (1978) The storage retrieval and classification of artefact shapes. In: Computer application in archaeology. Ottawa: Archaeological Survey of Canada. pp 39-48.

Mara, H. (2006) Documentation of rotationally symmetric archaeological finds by 3D shape estimation. Institute of Computer Aided Automation. Vienna: Vienna University of Technology.

Mazar, A. (2005). The debate over the chronology of the Iron Age in the Southern Levant: its history, the current situation, and a suggested resolution. In T. E. Levy \& T. Higham (Eds.), The bible and radiocarbon dating - archaeology, text and science (pp. 15-30). London: Equinox.

Mazar, A. (2011). The iron age chronology debate: is the gap narrowing? Another viewpoint. Near Eastern Archaeology, 74(2), 105-111.

Mazar, A., \& Bronk Ramsey, C. (2008). 14C dates and the iron age chronology of Israel: a response. Radiocarbon, 50, 159-180.

Oakeshott, M. F. (1978) A study of the Iron Age II pottery of East Jordan with special reference to unpublished material from Edom. University of London: Institute of Archaeology.

Orton, C., Tyres, P., et al. (1993). Pottery in archaeology. Cambridge: University Press.

Plog, S. (1980). Stylistic variation in prehistoric ceramics. Design analysis in the American Southwest. Cambridge: Cambridge University Press.

Porter, B. W. (2004). Authority, polity, and tenuous elites in iron age Edom (Jordan). Oxford Journal of Archaeology, 23, 373-395.

Pratico, G. D. (1993). Nelson Glueck's 1938-1940 excavations at Tell el-Kheleifeh-a reappraisal (Vol. 3). Atlanta: Scholars Press.

Ray, P. J. (2001) Tell Hesban and vicinity in the Iron Age. In Heshbon vol. 6. Berrien Springs: Andrews University. 
Razdan, A., D. Liu, et al. (2001) Using geometric modeling for archiving and searching 3D archaeological vessels. International Conference on Imaging Science, Systems, and Technology CISST 2001, Las Vegas.

Read, D. W. (1982). Towards a theory of archaeological classification. In R. Whallon \& J. A. Brown (Eds.), Essays in archaeological typology (pp. 56-92). Evanston: Center for American Archaeology Press.

Read, D. W. (2007). Artifact classification: a conceptual and methodological approach. Walnut Creek: Left Coast Press.

Rice, P. M. (1987). Pottery analysis: a sourcebook. Chicago: University of Chicago Press.

Sablatnig R., Menard C. (1997) 3D Reconstruction of archaeological pottery using profile primitives. In: Sarris N and Strintzis MG (eds.). Proc. of International workshop on synthetic-natural hybrid coding and three-dimensional imaging, pp. 93-96.

Saragusti, I., Karasik, A., et al. (2005). Quantitative analysis of shape attributes based on contours and section profiles in archaeological research. Journal of Archaeological Science, 32(6), 841-853.

Schurmans U, Razdan A, Simon A, McCartney P, Marzke M, Van Alfen D, Jones G, Rowe J, Farin G, Collins D, Zhu M, Liu D, Bae M, Tasdizen T, Tarel J, Cooper D (2001) Advances in geometric modeling and feature extraction on pots, rocks and bones for representation and query via the internet. In Proc. Of the 28th computer applications and quantitative methods in archaeology, CAA'01, April 25-29(2001).

Shennan, S. (1988). Quantifying archaeology. Edinburgh: University Press Edinburgh.

Shepard, A. O. (1965). Ceramics for the archaeologist. Washington: Carnegie Institute of Washington.

Smith, N. G. 2009. Social Boundaries and State Formation in Ancient Edom: A comparative ceramic approach. Unpublished PhD thesis. Department of Anthropology, University of California, San Diego.

Smith, N. G., \& Levy, T. E. (2009). The Iron Age pottery from Khirbat en-Nahas, Jordan: a preliminary study. BASOR, 352, 1-51.

Smith, N. G., \& Levy, T. E. (2012) Real-time 3D archaeological field recording: ArchField, an open-source GIS system pioneered in Jordan. Antiquity 85(331): http://antiquity.ac.uk/projgall/smith331/.

Stark, M. T., Elson, M. D., \& Clark, J. J. (1998). Social boundaries and technical choices in tonto basin prehistory. In M. T. Stark (Ed.), The archaeology of social boundaries (pp. 208-231). Washington, [D.C.]: Smithsonian Institution Press.

van der Leeuw, S. E. (1993). Giving the potter a choice: conceptual aspects of pottery techniques. In P. Lemonnier (Ed.), Technoloigcal choices: transformation in material cultures since the neolithic (pp. 238-88). London: Routledge.

Weiner, S. (2010). Microarchaeology: beyond the visible archaeological record. New York: Cambridge University Press.

Whallon, R., \& Brown, J. A. (Eds.). (1982). Essays in archaeological typology. Evanston: Center for American Archaeology Press.

Whiting, C. M. (2007). Complexity and diversity in the Late Iron age Southern Levant: the investigations of "Edomite" archaeology and scholarly discourse. Oxford: Archaeopress.

Whittaker, J. C., Caulkins, D., \& Kamp, K. A. (1998). Evaluating consistency in typology and classification. Journal of Archaeological Method and Theory, 5, 129-64.

Yao, F. and G. Shao (2003) Detection of 3D symmetry axis from fragments of a broken pottery bowl. Acoustics, Speech, and Signal Processing, 2003. Proceedings. (ICASSP '03) 3: 505-508. 